\title{
Stability of the Atlantic overturning circulation: \\ Competition between Bering Strait freshwater flux and Agulhas heat and salt sources
}

\author{
Wilbert Weijer, Wilhelmus P. M. De Ruijter and Henk A. Dijkstra \\ Institute for Marine and Atmospheric Research Utrecht \\ Utrecht University \\ Utrecht, the Netherlands
}

Accepted by J. Phys. Oceanogr.

Revised version of November 28, 2000

Corresponding Author:

Wilbert Weijer

Institute for Marine and Atmospheric Research Utrecht

Department of Physics and Astronomy

Utrecht University

Princetonplein 5, 3584 CC Utrecht

The Netherlands

Phone: ++31-30-2537759; Fax: ++31-30-2543163

Email: W.Weijer@phys.uu.nl 


\begin{abstract}
In this study we examine the role that is played by interocean fluxes of buoyancy in stabilizing the present-day overturning circulation of the Atlantic Ocean. A 2D model of the Atlantic overturning circulation is used, in which the interocean fluxes of heat and salt (via the Bering Strait, the Drake Passage and via Agulhas Leakage) are represented by sources and sinks. The profiles and amplitudes of these sources are based mainly on the heat and salt fluxes in a high-resolution ocean model (OCCAM).

When applying realistic sources and sinks, a circulation is favored that is characterized by major downwelling in the northern hemisphere (NPP circulation), and resembles the present-day Atlantic overturning circulation. The Southern Ocean sources appear to stabilize this circulation, whereas Bering Strait freshwater input tends to destabilize it. Already a small buoyancy input at southerly latitudes is enough to prohibit the existence of a southern sinking circulation (SPP), leaving the NPP circulation as a unique and stable solution. A large, factor three increase in Bering Strait freshwater import would be necessary to bring the SPP circulation back into existence.

Especially the Indian-Atlantic transfer of heat and salt, brought about by Agulhas Leakage, contributes considerably to the strength and, in particular, the stability of the northern sinking circulation. According to this model, shutting off Agulhas Leakage, and consequently the so-called warm water route for North Atlantic Deep Water (NADW) compensation, leads to a reduction of the overturning strength by $10 \%$ at most. These results imply that the way in which the NADW renewal takes place has implications for both the strength and stability of the Atlantic overturning circulation, giving the discussion about the warm vs. cold water route for NADW compensation dynamical significance.

Moreover, when the stabilizing effect of Agulhas Leakage on the overturning disappears, the destabilizing influence of the Bering Strait freshwater input becomes more effective. The system is then close to a regime where the northern and southern overturning circulations coexist as stable solutions. Perturbations in Bering Strait inflow may then easily lead to switches between the two circulation states. These results suggest that the absence of Agulhas Leakage during the last ice-age may have contributed to weakening the glacial overturning circulation in the Atlantic. It may have made the thermohaline circulation vulnerable to variability, caused either by regime switches, or by the excitation of oscillatory modes. The sudden restart of the Atlantic overturning circulation at the beginning of the Holocene may well have been stimulated by the coincident reopening of the Agulhas gap.

The presence of Agulhas Leakage may contribute to the relative stability of Holocene climate. Present-day climate may thus be more stable than previously thought.
\end{abstract}




\section{Introduction}

Palaeoclimatic records indicate that during the Pleistocene era of ice-ages climate instabilities have regularly interrupted the prevailing cold or warm conditions (e.g., Dansgaard et al. 1993). In view of this unstable climatic history, the stability of the Holocene is quite remarkable, and seems to be an exception, rather than the rule. The fear seems legitimate that our future climate, possibly modified by anthropogenic influences, may again become prone to instabilities. Determining the mechanisms of the climate instabilities during the past, and assessing the stability of present-day and future climate, is one of the main goals of climate research.

It is widely recognized that the large-scale ocean circulation to a large extent influences climate, and that it must have played a central role in shaping the past climatic instabilities (e.g., Broecker et al. 1985). Several hypothesis have been put forward to explain the Pleistocene instabilities from ocean circulation alone, without invoking ocean-ice interactions. Most of these hypothesis are based either on the presence of oscillatory modes, or of multiple equilibria. Oscillatory modes may evolve into stable limit cycles when they destabilize the underlying steady state via a Hopf-bifurcation (Weaver et al. 1993; Dijkstra and Molemaker 1997). If they are damped, they may be excited by stochastic components of the surface freshwater forcing (Griffies and Tziperman 1995; McWilliams 1996). Tziperman (1997) showed that in particular a weak thermohaline circulation is vulnerable to excitation of oscillatory modes. Especially the so-called flushing oscillations (e.g., Winton and Sarachik 1993), which are characterized by long episodes of diffusive destabilization of the abyssal ocean, and short episodes of catastrophic relaxation, may be considered as possible candidates for explaining Pleistocene climate variability, due to their long (millennial) time scales.

The other possible explanation of rapid climate fluctuations lies in the concept of multiple equilibria. Stommel (1961) discovered that thermohaline driven flow in an oceanic context may exhibit multiple equilibrium states under identical forcing. In the presence of multiple equilibria, finite-amplitude perturbations could trigger a switch from one equilibrium to another, resulting in a dramatic reorganization of the climate system (e.g., Broecker et al. 1985). Weaver and Hughes (1994) showed that switches between these equilibria may even be triggered by stochastic components of the surface (freshwater) forcing.

Multiple equilibria have been found in a large variety of models (see Rahmstorf et al. (1996) for an overview). Marotzke and Willebrand (1991), for instance, identified four equilibria in a simplified model of the Atlantic-Pacific circulation, characterized by deep water formation taking place either in the North Atlantic and/or in the North Pacific basin, or in the Southern Ocean. However, asymmetries between the Atlantic and Pacific strongly hinder the equilibria involving North Pacific downwelling (e.g., Stocker and Wright 1991ab; Stocker et al. 1992; Hughes and Weaver 1994), leaving only the states with downwelling either in the North Atlantic (northern sinking) or in the Southern Ocean (southern sinking) as candidates for regime switches.

In other models multiple equilibria are found that are characterized by a weaker 
or stronger North Atlantic overturning cell (e.g., Manabe and Stouffer 1988; Weaver and Hughes 1994; Rahmstorf 1994, 1996; Dijkstra and Neelin 2000). This is more in agreement with palaeoceanographic data, which suggest that during the last glacial period North Atlantic Deep Water (NADW) formation had not ceased, but was strongly reduced (e.g., Sarntheim et al. 1994). Rahmstorf (1994) has shown that in his Ocean General Circulation Model (OGCM) different strengths of the Atlantic overturning circulation were related to different distributions of the convective areas in the northern North Atlantic. Dijkstra and Neelin (2000) identified two equilibria resulting from north-south asymmetries in the basin geometry and in the surface freshwater flux of the Atlantic. They identified the strong overturning state as a conventional pole-to-pole circulation, that is thought to represent the present-day overturning in the Atlantic (e.g., Bryan 1986). The state with weak overturning turned out to be related to the thermally driven two-cell solutions featuring equatorial upwelling, found in models that have equatorial symmetry (e.g., Thual and McWilliams 1992; Dijkstra and Molemaker 1997). The asymmetries in the model of Dijkstra and Neelin (2000) cause a southward shift of the upwelling region, and a strengthening of the northern overturning cell.

If the combination of all north-south asymmetries in the Atlantic induces preference for the present-day overturning circulation to such an extent that it leaves it as the only stable circulation possible under present-day (and future) forcing, than our climate could be considered stable with respect to changes that may be expected in a global warming scenario, like melting of the Greenland ice-cap, enhanced Bering Strait through-flow (Shaffer and Bendtsen 1994), or an enhanced stochastic component in the surface freshwater forcing (Hughes and Weaver 1994). Furthermore, determining the windows in parameter space where multiple equilibria occur may provide the key to understanding rapid climate transitions in our Pleistocene past.

One aspect that induces north-south asymmetry in the Atlantic, and thus may influence the stability of the Atlantic overturning circulation, is the way the Atlantic exchanges water, heat and salt with the other ocean basins. Shaffer and Bendtsen (1994) were the first to explore the impact of North Atlantic interocean exchange (via Bering Strait) on the stability of the Atlantic overturning circulation. In their 3-box model, representing the North Pacific, the North Atlantic, and the rest of the World Ocean, they showed that the present-day conveyor belt circulation is not unique, and that a slightly increased freshwater inflow into the North Atlantic could destabilize the conveyor belt circulation in favor of a southern sinking state.

However, although the northern connection via the Bering Strait is interesting from a geographical point of view, being close to the vulnerable convection sites of the northern North Atlantic, the communication between the Atlantic and the other ocean basins is most intense in the Southern Ocean. Here the Atlantic exports its NADW by feeding it into the Antarctic Circumpolar Current (ACC). Part of this NADW ultimately returns as Subantarctic Water, entering the Atlantic through the Drake Passage with the ACC (i.e., the cold water route). This water forms the source of Antarctic Intermediate Water (AAIW), of which a part is finally converted into NADW (Rintoul 1991). Another part of the NADW export is compensated by input from the Indian Ocean via the process of 
Agulhas Leakage (i.e., the warm water route; Gordon 1985, 1986; see De Ruijter et al. 1999 for a review). How much of this Agulhas Leakage water is used for the production of about $20 \mathrm{~Sv}$ NADW is not known in detail, but a contribution of at least $4 \mathrm{~Sv}$ (Schmitz 1995) seems plausible. The highly contrasting water mass properties of the two possible renewal paths, via Drake Passage or via Agulhas Leakage, imply that the ratio of the contributions is important for the salt and heat balance of the Atlantic. Gordon et al. (1992) suggested that Agulhas Leakage could have dynamical impact on the meridional overturning circulation as well: the salt input salinifies the Atlantic surface waters and would precondition them for the formation of NADW. They even speculated: "if the Indian Ocean salt input were severed, might the NADW thermohaline cell run down?"

Circumstantial support for the hypotheses of Gordon et al. (1992) comes from palaeoceanographic data. Berger and Wefer (1996) pointed at the coincident establishment of a firm Atlantic overturning circulation at the end of the last ice-age, and the reappearance in the tropical Atlantic of a species of foraminifera, Globorotalia menardii. This species had been extinct in the glacial Atlantic, but not in the Indian Ocean. Its reappearance can only be explained by reseeding of the Atlantic from the Indian Ocean, suggesting a reopening of the Agulhas connection. Indeed, other palaeoceanographic studies indicate that during glacial times Agulhas Leakage was severely reduced, due to a more northerly position of the Subtropical Convergence Zone (STCZ, Howard and Prell 1992; Flores et al. 1999). Compared to the present-day wind field, a northward shift of only a few degrees would suffice to effectively shut off the connection between the Subtropical gyres of the South Indian and South Atlantic Oceans (De Ruijter 1982). Although no causality could be determined it is tempting to speculate that the reopening of Agulhas Leakage may have played a role in the sequence of events leading to the recovery of the overturning circulation.

Influence of interocean exchange on the Atlantic overturning circulation was recently demonstrated in a 2D model context (Weijer et al. 1999). In that study, interocean exchange was parameterized as lateral fluxes of heat and salt at the southern $\left(30^{\circ} \mathrm{S}\right)$ boundary of the model domain. The circulation turned out to be very sensitive not only to the integral of these fluxes, but also to their vertical distribution: both characteristics were shown to directly influence the energy balance of the flow. However, the approach did not allow for a systematic determination of the impact of each of the two paths of NADW renewal, the cold water route via the ACC, or the warm water route via Agulhas Leakage. Furthermore, the equatorial symmetry, that is to some extent present in the Atlantic, was broken, due to the asymmetry of the model domain (extending from $30^{\circ} \mathrm{S}$ to $60^{\circ} \mathrm{N}$ ). Since the northern sinking state was strongly favored by this (artificial) asymmetry, it could not be determined how Southern Ocean buoyancy fluxes influence the equilibrium structure of the Atlantic thermohaline circulation.

The goal of this study is to investigate how Southern Ocean interocean exchange modifies the strength and stability of the northern sinking circulation, and what role is played by the different sources of NADW renewal. In particular we focus on the impact of Agulhas Leakage, to determine whether the presence of the warm (and salty) water path of NADW renewal has dynamical influence on the overturning circulation, 
as suggested by Gordon et al. (1992). The stability of the overturning circulation is tested under influence of the Southern Ocean sources, and with respect to Bering Strait freshwater input. The model used is basically identical to the 2D Boussinesq model used in Weijer et al. (1999). Here, the domain ranges from $60^{\circ} \mathrm{S}$ to $60^{\circ} \mathrm{N}$ so that the basic equatorial symmetry is retained. Furthermore, the interocean fluxes of heat and salt from the two different NADW compensation routes are distinctively represented as source or sink distributions. This allows for estimating the impact of the warm and cold water routes of NADW renewal.

Over the years, 2D models have proven their usefulness and have increased our understanding of the thermohaline overturning circulation. Of course, the large simplifications limit the model's quantitative applicability to the ocean circulation, and make the model suitable for testing and exploring conceptual ideas, rather than for making quantitative estimates of the stability of the ocean circulation. The use of a 2D model in this study is partly motivated by its relatively low number of degrees of freedom, allowing it to be coupled to a continuation code that enables a systematic study of all (including the unstable) equilibria in a relevant volume of parameter space.

Another motivation is more fundamentally related to the problem that is addressed. Studying the impact of interocean exchange on the overturning circulation in global $3 \mathrm{D}$ models is complicated, since interocean fluxes of heat and salt are closely linked to the exchange of water in the global thermohaline circulation. These fluxes cannot be varied independently without somehow decoupling them from the circulation itself. We hereby assume that it is not the exchange of mass that is likely to exert most influence on the Atlantic overturning circulation, but rather the associated exchange of heat and salt: it probably does not matter whether NADW returns via Agulhas Leakage or the Drake Passage, were it not for their different temperature and salinity characteristics.

In the 3D modeling study of Weijer et al. (2000) this decoupling was accomplished for the heat and salt exchange brought about by Agulhas Leakage. The absence of actual Agulhas Leakage in the (low-resolution) model allowed for considering the Leakage, as well as its compensation by NADW or South Atlantic Current water export, as subgrid-scale processes. The resulting subgrid-scale exchange of heat and salt was conceived and parameterized as sources, localized in the Agulhas Retroflection area, whose amplitudes could be varied systematically. However, the exchange between the ACC and the South Atlantic takes place mainly by subtle entrainment and mesoscale mixing processes along the frontal zones in the Atlantic sector of the Southern Ocean (e.g., Park and Gamberoni 1997; Boebel et al. 1999). Since this exchange is not localized, it is hard, if not impossible, to parameterize in a 3D model context in a way that is physically meaningful and acceptable.

One way to avoid the need of specifying this exchange explicitly is to perform zonal integration. In this way, the amount of heat and salt that is exchanged between the ACC and the Atlantic can be estimated by comparing the fluxes by the ACC upon entering the Atlantic through Drake Passage, and upon leaving the Atlantic across, say, $20^{\circ} \mathrm{E}$. Although the resulting flux differences are to some extent influenced by processes like air-sea exchange (an effect that will be accommodated by the boundary fluxes in the 
model) and local upwelling (Weijer 2000), we assume that their vertical distributions and integral values mainly reflect the exchange processes between the Atlantic and the ACC. The resulting zonally integrated representation of exchange processes between the Southern Ocean and the South Atlantic make the fluxes pre-eminently suitable for use in a $2 \mathrm{D}$ model context.

In section 2 the model is described, as well as the sources that are used to parameterize the interocean exchange of heat and salt. The distributions of these sources are based on the interocean fluxes in the high-resolution OGCM OCCAM (Webb et al. 1998). In section 3 the model is forced with the South Atlantic interocean fluxes, and the sensitivity of the overturning strength is studied for different scenarios of NADW compensation. Furthermore, the stability of this circulation is studied with respect to freshwater input through the Bering Strait. Summary and discussion of the results follow in section 4 .

\section{Model set-up}

\section{$2.1 \quad$ The model}

[Table 1 about here.]

The model that is used to study the influence of the heat and salt source/sink distributions has been described in Weijer et al. (1999). The present configuration models the overturning circulation in the Atlantic Ocean from $60^{\circ} \mathrm{S}$ to $60^{\circ} \mathrm{N}$. Latitude and depth are non-dimensionalized through $\theta=60(2 y-1)$ and $\tilde{z}=H(z-1)$. The momentum equations are solved in a streamfunction/vorticity formulation:

$$
\begin{aligned}
\Omega & =-a^{2} \psi_{y y}-\psi_{z z} \\
\operatorname{Pr}^{-1}\left(\frac{\partial \Omega}{\partial t}-J(\psi, \Omega)\right) & =R a(T-S)_{y}+\Omega_{y y}+\Omega_{z z}
\end{aligned}
$$

where $\psi$ and $\Omega$ are the dimensionless streamfunction and vorticity, and $J(a, b)$ denotes the Jacobian operator $a_{y} b_{z}-a_{z} b_{y}$. The Prandtl number $\operatorname{Pr}$, the aspect ratio $a$, and the Rayleigh number $R a$ are given values $2.25,5 \cdot 10^{-4}$, and $1 \cdot 10^{4}$, respectively (Table 1 ).

The influence of the Agulhas Leakage and the ACC on the heat and salt balance is modeled by heat and salt source distributions $Q^{(T, S)}$. The dimensionless advectiondiffusion equations for heat and salt are:

$$
\begin{aligned}
& \frac{\partial T}{\partial t}+v T_{y}+w T_{z}=T_{y y}+T_{z z}+Q^{T} \\
& \frac{\partial S}{\partial t}+v S_{y}+w S_{z}=S_{y y}+S_{z z}+Q^{S}
\end{aligned}
$$

[Figure 1 about here.] 
The model is forced at the surface with a prescribed surface salt flux:

$$
-\frac{\partial S}{\partial z}=\sigma_{s} F^{S}(y)+I^{S}
$$

It consists of a net salt flux component $I^{S}$, and a spatial profile $F^{S}(y)$ with amplitude $\sigma_{s}$ and zero integral. The profile $F^{S}(y)$ (Fig. 1) is symmetrical with respect to the equator, and is given by:

$$
F^{S}(y)=-\cos \left(\frac{\pi}{60} \theta(y)\right)+2.4 \exp \left[-\left(\frac{\theta(y)}{12}\right)^{2}\right]-0.24 \sqrt{\pi} \operatorname{erf} 5
$$

Surface temperature is restored towards a fixed atmospheric temperature profile $T^{*}$, given by (Fig. 1):

$$
T^{*}(y)=0.5+0.5 \cos 3 y
$$

The surface heat flux is thus given by:

$$
-\frac{\partial T}{\partial z}=b_{T}\left(T-T^{*}(y)\right)
$$

The relaxation constant $b_{T}$ is set at 100 , a value that is characteristic for OGCMs (Dijkstra and Molemaker 1997).

\subsection{The sources}

The sources in Eq. (2) are split into an Agulhas component and an ACC component. The amplitudes of these sources can be varied independently via $\tau$ and $\sigma$ :

$$
\begin{aligned}
& Q^{T}(y, z)=\tau_{a g u} Q_{a g u}^{T}(y, z)+\tau_{a c c} Q_{a c c}^{T}(y, z) \\
& Q^{S}(y, z)=\sigma_{a g u} Q_{a g u}^{S}(y, z)+\sigma_{a c c} Q_{a c c}^{S}(y, z) .
\end{aligned}
$$

The spatial integrals of the distribution functions equal 1 , so that $\tau_{q}$ and $\sigma_{q}$ represent the net exchange by that particular source component. The (dimensionless) amplitudes $\tau$ and $\sigma$ and the distribution functions $Q^{T}$ and $Q^{S}$ can be related to the 'real' sources of heat and salt that are implied by interocean exchange, but these are hardly known. Since no sufficiently detailed information about the spatial distribution of these interocean fluxes have been found in the literature, the climatology of the high-resolution OGCM OCCAM (Webb et al. 1998) is used. In Appendix A the analysis of the interocean exchange processes in OCCAM is presented. In Appendix B it is shown how the interocean fluxes in OCCAM are used to determine the amplitudes of the sources as used in Eq. (7).

[Table 2 about here.]

[Table 3 about here.] 
Tables 2 and 3 show the dimensional and dimensionless source amplitudes implied by the OCCAM interocean fluxes, in combination with a realistic Bering Strait salt transport (Coachman and Aagaard 1988), and a 0.5 Sv surface freshwater export (Baumgartner and Reichel 1975). However, the salt sources and sinks do not add up to 0, so that the salt balance:

$$
\sigma_{a g u}+\sigma_{a c c}+\sigma_{b s}-I^{S}=0
$$

does not hold. This is partly due to geometric effects like the irregular width of the Atlantic basin and the convergence of meridians. This impedes a consistent mapping of the fluxes on a meridional strip of constant width. For another part, the non-zero sum of the fluxes is caused by storage of salt in the OCCAM model, and the residual transports that were not included in the calculation (i.e., eddy fluxes and diffusion). The values of $\sigma_{a g u}$ and $\sigma_{a c c}$ were determined from the OCCAM climatology, and are probably least representative for the real ocean. The choice was made to adjust the strength of the ACC salt source so that it matches the sum of the other sources. When Bering Strait salt export is included, the ACC salt sink is reduced according to $\sigma_{a c c}=3-\sigma_{b s}$.

[Figure 2 about here.]

In Appendix $\mathrm{C}$ the construction of the source distributions is described. Analytical functions are fitted to the profiles derived from the OCCAM model. A spatial view on the resulting source/sink distributions is provided by the wire plots of Fig. 2, which show the heat and salt sources of the Agulhas and the ACC with (dimensionless) amplitudes \pm 1 . The Agulhas heat source profile shows strong heat input in the subsurface layer, whereas the ACC heat sink profile is characterized by heat export from the upper layer. A slight heat input is present at intermediate levels. The Agulhas salt flux profile is characterized by strong salt input at shallow levels and a vertically homogeneous salt input at deep and bottom water levels. At intermediate depths there is a minimum in eastward salt transport. The ACC salt source shows a similar structure, but of opposite sign. It features a shallow salt export, an input of salt at intermediate depths, and a small export at the deeper levels.

The Bering Strait salt flux is modeled by a lateral salt flux through the northern boundary of the domain. The profile is taken to be exponential in the vertical, so that:

$$
-\frac{\partial S}{\partial y}=F_{b s}^{S}=-\sigma_{b s} \frac{c}{1-e^{-c}} e^{c(z-1)} .
$$

Note that negative values of $\sigma_{b s}$ denote salt export. The parameter $c$ is given the value 17 , so that its corresponding depth scale of about $300 \mathrm{~m}$ is characteristic of the depth of the shallow overflow ridges in the northern North Atlantic.

For convenience, the source amplitudes will be given in dimensional units ( $\mathrm{PW}$ or $\mathrm{Sv}$ psu) throughout the rest of this paper. The conversion factors between the dimensionless and dimensional amplitudes (denoted by $\mathrm{a}^{*}$ ) are given in Tables 2 and 3. 


\section{Results}

\subsection{The standard experiment (no Bering Strait flux)}

[Figure 3 about here.]

Figure 3 shows the streamfunction, temperature and salinity fields of the solution that is forced with the standard source configuration, according to Tables 2 and 3. Bering Strait salt export has not been included at this point $\left(\sigma_{b s}^{*}=0\right)$. The amplitude of the surface salt flux $\sigma_{s}$ is set at 10 , which is roughly equivalent to $35 \cdot 10^{-9} \mathrm{~ms}^{-1}$ or 1100 $\mathrm{mm} \mathrm{yr}^{-1}$ (Weijer et al. 1999). This is a characteristic amplitude for estimates of the zonally averaged $E-P$ in the Atlantic (e.g., Zaucker et al. 1994).

The steady-state circulation for these parameter values is characterized by a strong overturning with downwelling in the northern part of the domain. The overturning strength, as measured by the maximum value of the streamfunction $\psi_{\text {max }}$, is 10.5 in dimensionless units. With the dimensional streamfunction $\psi^{*}$ being related to its scaled counterpart via $\psi^{*}=\kappa_{v} L / H \psi$ (Weijer et al. 1999), this corresponds to a dimensional streamfunction of about $0.27 \mathrm{~m}^{3} / \mathrm{s}$ per longitudinal meter, or, if applied to a basin of $60^{\circ}$ wide, a transport of $19 \mathrm{~Sv}$. This overturning strength agrees well with the $20 \mathrm{~Sv}$ estimate of Broecker (1991).

The temperature field (Fig. 3, middle panel) shows a well developed thermocline. The strong Agulhas source is responsible for the subsurface temperature maximum at $\theta=40^{\circ} \mathrm{S}$. The salinity field displays a strong minimum at the most southerly latitudes, where the ACC salt sink extracts salt from the Atlantic. From this fresh pool a lowsalinity tongue is advected northward to within the Subtropics. This feature resembles the northward penetration of the relatively fresh AAIW into the Atlantic (e.g., Levitus 1982).

[Figure 4 about here.]

Comparison of the model's surface salinities (Fig. 4, 'no Bering Strait') with observations ('Levitus') shows that the position and amplitudes of the Subtropical maxima and tropical minimum are well reproduced. The low salinities in the ACC region reflect the fact that the amplitude of the ACC salt sink is increased with respect to the OCCAM estimate to close the salt balance. This approach has disproportionally increased the salt export at shallow levels; closure of the salt balance by a vertically homogeneous correction might have resulted in a more realistic sea surface salinity.

The model's North Atlantic salinities are, on the contrary, too high with respect to the observations. Inclusion of the Bering Strait salt export at the northern boundary of the domain (with a realistic amplitude $\sigma_{b s}^{*}=-2.0 \mathrm{~Sv}$ psu) does not result in the necessary freshening of the North Atlantic (Fig. 4, 'Bering Strait'). It is probable that the absence of zonal structures in this model is partly responsible for this discrepancy: in this model, southward penetration of the Bering Strait freshwater input is inhibited by the northward flow of the overturning circulation. In the real ocean, however, meridional 
transports of salt and freshwater are accomplished by the wind-driven circulation as well. This would allow the freshwater input from the Arctic Ocean to be advected southward, in spite of the northward transport induced by the overturning circulation.

\subsection{Impact of Agulhas Leakage}

Starting from the standard solution, we decrease both the amplitude of the Agulhas heat and salt sources to study the response of the overturning circulation to changes in the so-called warm water route. Upon reducing the strength of the Agulhas heat source from 1.1 to $0 \mathrm{PW}\left(\tau_{a g u}\right.$ from 6 to 0$)$ the surface heat flux adjusts itself in such a way that the heat balance remains closed. The reduction of the Agulhas heat input thus results in a reduced net surface heat loss. The strength of the overturning circulation drops from 19 to $13 \mathrm{~Sv}$, reflecting an averaged sensitivity of $5 \mathrm{~Sv}$ per PW.

For salinity, however, the surface flux is prescribed and cannot adjust to close the balance. So when reducing the Agulhas salt input from 11.4 to $0 \mathrm{~Sv}$ psu $\left(\sigma_{a g u}\right.$ from 1 to 0 ), a choice must be made where the reduced salt input is compensated. This choice is not obvious. The net surface freshwater flux is determined by the difference between precipitation and evaporation in the catchment area of the Atlantic, and it is not very likely that it depends markedly on the presence or absence of Agulhas salt input. It is likely that net evaporation is influenced to some extent by the Agulhas heat input in the South Atlantic, but reduction of this heat input, and thus the excess evaporation, leads to a decrease in the (virtual) surface salt input.

[Figure 5 about here.]

It is probable that shutting off Agulhas Leakage would result in a reduced salt export in the ACC region. Three possible scenarios are tested to get an idea of the tendency of the response, and of possible sensitivities. These scenarios keep the amplitude $\sigma_{a c c}$ of the ACC salt sink profile constant: the reduction in the export is accomplished by addition of an extra salt source to this ACC profile. The scenarios differ in the vertical distribution of this additional source, and thus represent different scenarios for NADW renewal (Fig. 5).

Cold water scenario A vertically homogeneous salt source is added in the upper 2500 $\mathrm{m}$ of the ACC region. This case mimics a dominant role of the so-called 'cold water route' for NADW renewal, since the salt that is imported in the Agulhas region does not leave the Atlantic in the form of NADW, but at shallower levels. It may leave with the South Atlantic Current, or it may end up in the upper layers of the ACC by cross-frontal exchange at the Brazil-Malvinas Confluence Region (Boebel et al. 1999).

Hybrid scenario A vertically homogeneous salt source is added over the whole depth range in the ACC region. The resulting reduction in the net salt export is now homogeneously distributed over the whole depth range. Both interpretations of the cold and warm water scenarios now partly apply. 
Warm water scenario The additional salt source is now applied over the deeper half of the domain. In this scenario all Agulhas salt input leaves the Atlantic with the NADW, so that reduction of this input results in reduced deep salt export. Since the participation of Agulhas Leakage water in forming NADW is now considerable, it mimics the so-called 'warm water route' of NADW renewal.

[Figure 6 about here.]

Figure 6 shows that a reduced Agulhas salt input reduces the Atlantic overturning circulation if at least a part of the Agulhas Leakage water participates in the NADW production (hybrid and warm water scenarios). A vertically homogeneous compensation (hybrid) reduces the overturning strength with $1 \mathrm{~Sv}$, while a deep compensation (warm water scenario) reduces the strength even with $2.3 \mathrm{~Sv}$ (i.e., $12 \%$ ). In the case of a shallow compensation (cold water scenario) the overturning strength is almost unchanged.

The response of the overturning circulation to the Agulhas heat and salt sources can be understood by looking at their impact on the energy balance of the system (Weijer et al. 1999). In Appendix D it is shown that the Agulhas heat source, in combination with the associated surface cooling, supplies potential energy to the system. This energy is converted into kinetic energy and is used to strengthen the overturning circulation. If balanced by a deep salt sink, the Agulhas salt source supplies potential energy as well. If, on the other hand, it is balanced by a shallow salt sink the supply of potential energy is nihil. This explains the strong sensitivity of the overturning circulation to the Agulhas source amplitude in the warm water scenario, and the negligible response in the cold water scenario (Fig. 6).

\subsection{Uniqueness of the standard solution}

[Figure 7 about here.]

[Figure 8 about here.]

In this section it is shown that the northern sinking solution that is forced by the standard source configuration is unique in the sense that no other equilibria are found under the same forcing conditions. To this end we study how the bifurcation structure of the symmetrical model is changed when sources and sinks of heat and salt are applied. Figure 7 shows the bifurcation diagram of the system that has reflective symmetry with respect to the equator, and for which all source amplitudes $\sigma_{a g u}^{*}$, etc. are zero. The streamfunction in the right-hand side of the domain $\left(\psi_{r h s}^{*}\right)$ is computed to monitor the solution when the amplitude of the surface salt flux is modified. For low values of this salt forcing, only a thermally driven solution (TH) exists, that is symmetrical and displays downwelling at both poles (Fig. 8, upper panel). At the (subcritical) pitchfork bifurcation $P_{1}$ this solution loses stability, and two asymmetrical solutions branch off. These solutions are characterized by downwelling at the northern (NPP, Fig. 8, middle panel) or southern (SPP) polar region, and they become stable at the limit points $L_{N}$ 
and $L_{S}$. These solutions recombine with the symmetrical branch at the (supercritical) pitchfork bifurcation $P_{2}$. Beyond $P_{2}$ only a salinity driven circulation (SA, Fig. 8, lower panel) exists, with downwelling in the evaporative Subtropical regions, and upwelling at the equator and the poles.

[Figure 9 about here.]

[Figure 10 about here.]

When a buoyancy source or sink is applied at the latitudes where the Atlantic interacts with the rest of the World Ocean, say in the Agulhas region, the equatorial symmetry of the model is broken. Figure 9 shows the resulting bifurcation diagrams when an Agulhas heat source is applied, with a purely exponential shape in the vertical (according to Eq. (C4) and Table C1, but with $\left.a_{4}=0\right)$, and a positive $\left(\tau_{a g u}^{*}=0.02 \mathrm{PW}\right.$, upper panel) or negative $\left(\tau_{a g u}^{*}=-0.02 \mathrm{PW}\right.$, lower panel) amplitude. The plots clearly show that the pitchfork bifurcations $P_{1}$ and $P_{2}$ disappear, and new limit points $L_{1}$ and $L_{2}$ arise.

When the positive heat source is applied, the NPP circulation is connected to the TH branch via the limit points $L_{N}$ and $L_{1}$, and a small branch of unstable solutions. For slightly larger source amplitudes, these limit points merge, rendering the transformation of the TH solution into the NPP solution continuous. For large values of $\sigma_{s}$ the NPP branch is continuously connected to the salinity driven solutions (SA). The SPP solution has become isolated, and can only exist in the window bounded by limit points $L_{S}$ and $L_{2}$. For larger values of $\tau_{a g u}^{*}$, this window shrinks drastically, until at $\tau_{a g u}^{*}=0.06 \mathrm{PW}$ $\left(\tau_{a g u}=0.31\right)$ these limit points merge into a single isolated point in parameter space (Fig. 10, upper panel, dashed line). For higher values of $\tau_{a g u}^{*}$, the region of multiple equilibria disappears, and the NPP solution is the only circulation that is possible for a realistic value of the surface salt flux $\left(\sigma_{s}=10\right)$.

For a negative heat source $\left(\tau_{\text {agu }}^{*}=-0.02 \mathrm{PW}\right.$, Fig. 9, lower panel), the roles of NPP and SPP are reversed, so that the NPP branch becomes isolated. The limit points $L_{N}$ and $L_{2}$ merge at about $\tau_{a g u}^{*}=-0.04 \mathrm{PW}\left(\tau_{a g u}=-0.23\right.$, Fig. 10, upper panel, solid line), so that the NPP solution ceases to exist below this value.

The break-up of the original bifurcation diagram under the influence of a salt source is comparable to the thermal case. Figure 10 (lower panel) shows, however, that the amplitudes beyond which the NPP $\left(\sigma_{a g u}>0.06\right.$, or $0.7 \mathrm{~Sv}$ psu $)$ and the $\mathrm{SPP}\left(\sigma_{a g u}<-0.07\right.$, or $-0.8 \mathrm{~Sv}$ psu) cease to exist are considerably smaller than their thermal counterparts. Evidently, the existence of the pole-to-pole circulation patterns is more sensitive to saline than to thermally induced asymmetries.

[Figure 11 about here.]

The regime diagram of Fig. 11 shows the areas in $\sigma_{a g u}^{*}-\tau_{a g u}^{*}$-space where NPP and SPP solutions (co)exist. The standard source configuration features a net heat source of roughly $0.74 \mathrm{PW}\left(\tau_{a g u}^{*}+\tau_{a c c}^{*}\right)$ and a net salt sink of about $-21.2 \mathrm{~Sv}$ psu $\left(\sigma_{a g u}^{*}+\sigma_{a c c}^{*}\right)$. This places its NPP solution far in the upper-left quadrant of Fig. 11 (indicated by 
the upper arrow), well outside the existence area of the SPP solutions. The configuration without Agulhas heat and salt sources features both a net heat and salt export $\left(\tau_{a c c}^{*}=-0.34 \mathrm{PW}, \sigma_{a c c}^{*}=-32.6 \mathrm{~Sv} \mathrm{psu}\right)$, and corresponds to a point in the lower-left quadrant of the plot (indicated by the lower arrow). It is situated well above the line separating the NPP and the NPP/SPP areas. This means that the buoyancy fluxes brought about by interocean exchange in the Southern Ocean favor the northern sinking solution considerably. The imposed asymmetries furthermore inhibit the existence of the southern sinking solutions, making regime switches from a northern sinking to a southern sinking circulation unlikely.

\subsection{Multiple equilibria in the presence of Bering Strait inflow}

In the previous section we have seen that the exchange of buoyancy between the Atlantic and the rest of the World Ocean via the Southern Ocean strongly favors the northern sinking circulation state. It even dispels the competing southern sinking solution from the area in parameter space that may be considered as representative for the real ocean. However, the Atlantic also exchanges freshwater with the Pacific via the Bering Strait, and it is conceivable that the freshwater input into the North Atlantic hinders the northern sinking circulation. In this section we study how the areas of existence of the NPP and SPP solutions are influenced by Bering Strait freshwater import. The strength of the Bering Strait salt export is controlled by the parameter $\sigma_{b s}^{*}$. In the experiments, the amplitude of the ACC salt sink is adjusted to satisfy the balance of Eq. (8).

[Figure 12 about here.]

[Figure 13 about here.]

Figure 12 shows $\psi_{r h s}^{*}$ as function of the Bering Strait salt export $-\sigma_{b s}^{*}$ for three different source configurations. The curve denoted 'ACC+Agulhas' is constructed with the standard source configuration of Tables 2 and 3. The northern sinking circulation pattern, that is so firmly established in the standard source configuration with $\sigma_{b s}^{*}=0$, is stable with respect to a very large Bering Strait freshwater input (Fig. 13, upper panel). Only when the amplitude exceeds the value of $6.7 \mathrm{~Sv}$ psu a counter-rotating cell develops, that rapidly expels the main overturning cell towards the south (Fig. 13, middle panel). On the branch of unstable solutions, between the limit points at $-\sigma_{b s}^{*}=11.3$ and $5.2 \mathrm{~Sv}$ $\mathrm{psu}$, the clockwise rotating cell is eliminated completely. The southern sinking solution that is established (Fig. 13, lower panel) is stable for $-\sigma_{b s}^{*}>5.2 \mathrm{~Sv}$ psu.

Reducing Agulhas Leakage heat and salt sources towards zero (i.e., switching from the 'ACC+Agulhas' branch to 'ACC only') strongly reduces the strength of the overturning circulation, as has been shown in the former section. This reduction has large consequences for the stability of the circulation with respect to Bering Strait freshwater input. The curve denoted 'ACC only' in Fig. 12 shows a dramatic shift in the position of the limit points. The limit point with the lowest value of $-\sigma_{b s}^{*}$ shifts towards $2.1 \mathrm{~Sv} p s u$, 
and is now close to the value of $2.0 \mathrm{~Sv}$ psu that may be considered representative for the present-day situation. This suggests that shutting off Agulhas Leakage could drag the overturning circulation close to a regime where southern sinking solutions might exist under the same surface forcing. Finite amplitude disturbances (like freshwater input from a melting Greenland ice sheet) might induce a dramatic shift.

Figure 12 confirms the findings of the former section that the NPP solution is unique when it is forced by the standard source configuration (with $\sigma_{b s}^{*}=0$ ). The curve denoted 'no sources' was created in the absence of the Southern Ocean buoyancy sources, and shows three zero-crossings that correspond to three points on the bifurcation diagram of the model with equatorial symmetry (Fig. 7, at $\sigma_{s}=10$ ). It thus connects the NPP branch, via the unstable TH/SA solutions, with the SPP branch. Upon introducing the Southern Ocean sources, the curve 'no sources' transforms into the curves 'ACC only' or 'ACC+Agulhas', and the two zero-crossings that are associated with the TH/SA and SPP branches disappear. This leaves NPP as the only possible solution for $\sigma_{b s}^{*}=0$.

\section{Summary and discussion}

In this paper we studied the impact of interocean fluxes of heat and salt on the strength and stability of the thermohaline circulation in the Atlantic Ocean. We forced a 2D model of the Atlantic overturning circulation with source/sink distributions of heat and salt representing the exchange between the Atlantic and the rest of the World Ocean via the ACC and via Agulhas Leakage. The profiles of these distributions are based on the climatology of the high-resolution ocean model OCCAM, since no sufficiently detailed information about the spatial structure of interocean fluxes was found in the literature. Although a detailed analysis of the interocean exchange in this model (Weijer 2000) has shown some unrealistic features when compared with observations, it was concluded that the large-scale transports and thermohaline structure are reasonably well reproduced. This justifies the use of the OCCAM flux profiles as a basis of the source distributions.

The Southern Ocean source configuration reflecting best the present-day interocean exchange appeared to promote the overturning circulation with northern sinking in this model. Only a weak Southern Ocean buoyancy source turned out to be enough to inhibit the southern sinking solution from existing, so that in this model the northern sinking solution is unique under present-day forcing conditions. A very large (factor three) increase in the relatively fresh inflow through Bering Strait (or some other freshwater source in the north) is necessary to bring the model back into a regime where multiple equilibria exist.

Especially the Indian-Atlantic interocean exchange through Agulhas Leakage turned out to be an important stimulus of the northern sinking circulation. In this model, Agulhas heat input promotes the overturning circulation mainly by the potential energy supply that is implied by its (subsurface) heat source. This potential energy is released and converted into kinetic energy of the flow (Weijer et al. 1999). The impact of Agulhas salt input on the overturning strength depends on its fate: if Agulhas Leakage 
water participates in the overturning circulation, so that its salt leaves the Atlantic with NADW, it strongly promotes the overturning circulation due to the associated potential energy release. If, on the other hand, Agulhas Leakage water does not participate in the overturning circulation, its salt recirculates in the South Atlantic Subtropical Gyre, and leaves the Atlantic on approximately the same level on which it entered (with the South Atlantic Current or the ACC); its influence on the overturning circulation is consequently small. These results impose dynamical significance to the discussion about how NADW export is compensated (see e.g., Gordon et al. 1992). They indicate that it is important for the Atlantic overturning circulation whether the source water of NADW has entered the Atlantic through Drake Passage, with cold and fresh Subantarctic characteristics, or via Agulhas Leakage, with warm and salty (sub)tropical qualities.

One caveat must be mentioned. The source distributions that were used in this model represent fluxes that are consistent with, and to a certain extent generated by, the present-day overturning circulation. And since this circulation is clearly in a northern sinking state, the imposed asymmetry is not independent of the present-day circulation. If an alternative circulation pattern would generate interocean fluxes that are different, and favorable for that particular state, then the stability of these states would have been underestimated by the approach used here. The northern sinking state would have been biased by the choice of the sources. That this is the case for temperature is almost beyond doubt: the equatorward heat flux, a feature that is unique to the South Atlantic, is to a large extent generated by the overturning circulation (e.g., Rintoul 1991).

On the other hand, not all processes generating interocean transports are necessarily connected to the overturning circulation. Agulhas Leakage is probably a predominantly wind-driven feature, although it is possible that interoceanic pressure differences, induced by thermohaline processes, to some extent assist in this exchange (De Ruijter et al. 1999). It is probable that the Agulhas heat input influences the South Atlantic stratification and the atmospheric heat flux, independent of whether Agulhas Leakage water participates in the Atlantic overturning circulation. So even if no Agulhas Leakage water would take part in the overturning circulation, it would probably still sustain a net input of heat and salt and thus influence the large scale pressure field and overturning strength. Nevertheless, even if the northern sinking state is biased by the fact that the sources are diagnosed from a model circulation that is in this state, it is clear that the interocean fluxes brought about by this circulation pattern provide a strong stabilizing factor.

Our 2D model of the Atlantic overturning circulation, coupled to a continuation code, turned out to be an efficient and effective tool for studying parameter sensitivities. Furthermore, it allowed for decoupling the interocean fluxes of heat and salt from the exchange of water between the several ocean basins, and for parameterizing these fluxes as sources with controllable amplitudes and distributions. Nevertheless, the large simplifications of the model make it useful to test and explore conceptual ideas, rather than to make a quantitative estimate of the stability of the ocean circulation. Several 
limitations of the model may be mentioned that are likely to have quantitative impact on the stability characteristics of the solutions. But how and to what extent these effects modify the stability quantitatively, and whether they are strong enough to change our (qualitative) conclusions on the preference of the NPP circulation, has to be studied with more realistic (preferably 3D global coupled) models.

The fixed surface freshwater flux, for instance, does not take into account that the Southern Ocean heat exchange may influence evaporation and precipitation rates in the Atlantic. Thus both the strength of the Atlantic freshwater cycle (i.e., $\sigma_{s}$ in our model), and the excess evaporation over precipitation $\left(-I^{S}\right)$ may not be independent of the Southern Ocean heat sources. Also the degree of equatorial asymmetry of the freshwater flux distribution (see also Dijkstra and Neelin 2000) may to some extent be influenced by these sources. Other limitations arise from the two-dimensionality of the model, and include absence of realistic geometry, Coriolis effects, wind stress, and, in our case, a realistic geographic representation of the sources. The approach of projecting the ACC and Agulhas fluxes on a meridional plane resulted in partly overlapping and cancelling source distributions, doing no justice to the fact that the fluxes are a result of complex mixing processes taking place over the entire width of the South Atlantic. However, it is hard, if not impossible, to parameterize and control these processes in a $3 \mathrm{D}$ model, so we believe that our approach is reasonable.

Since Agulhas Leakage depends on characteristics of the Indian Ocean wind stress field (De Ruijter et al. 1999), it may be rather sensitive to changes in the wind climatology. Agulhas Leakage was probably severely reduced during the last glacial, due to a more northerly position of the STCZ (Howard and Prell 1992; Flores et al. 1999). The results of this study show that this may have played a role in reducing the strength of the overturning circulation in the glacial Atlantic. Besides, absence or reduction of Agulhas Leakage may have made the glacial circulation more susceptible to regime switches and instabilities. Figure 12 shows that reducing the stabilizing influence of Agulhas Leakage brings other circulation regimes back into the picture. This enables regime switches, either forced by finite-amplitude disturbances, or by stochastic components of the surface freshwater forcing (Weaver and Hughes 1994). Furthermore, a weaker overturning may be more susceptible to excitation of damped oscillatory modes, as found by Tziperman (1997). Our results furthermore support the suggestion of Berger and Wefer (1996) that the common start-up of NADW production and the opening of Agulhas Leakage at the end of the last ice-age could have been more than just a simultaneous response to external forcing: a restart of Agulhas Leakage, due to a southward shift in the position of the STCZ, may have stimulated the recovery and stabilization of the conveyor belt circulation.

Reconstructions of glacial deep water circulation not only suggest that the northern sinking overturning circulation was reduced in strength (rather than absent or reversed), but also that the source region of NADW was shifted to regions south of Iceland (Keigwin et al. 1991; Sarntheim et al. 1994). Manabe and Stouffer (1988) and Rahmstorf (1994) explained the reduction in overturning strength by transitions between equilibria with weaker and stronger overturning circulations, as found in several models (e.g., 
Manabe and Stouffer 1988; Weaver and Hughes 1994; Rahmstorf 1994, 1996; Dijkstra and Neelin 2000). However, none of these transitions seem to produce a southward shift of the downwelling region. Figure 12 shows a transition that might explain the glacial North Atlantic climate changes. This transition is related to a southward shift of the main downwelling area from the northern polar region (Fig. 13, upper panel) to the Subtropics (Fig. 13, middle panel). Although this transition in the present configuration does not involve limit-points and hysteresis behavior, the heat transport towards the northern North Atlantic region is reduced abruptly, once the downwelling site has left the North Atlantic subpolar regions.

Figure 12 shows that the transition requires an increased freshwater input into the northern North Atlantic, which is not consistent with the situation during the last glacial when Bering Strait was closed. Nevertheless, this mode may have played a role in generating the brief episodes of cooler climate in Europe at the end of the last glacial period (including the Younger Dryas event). Palaeoclimatic records indicate that these events of reduced NADW production coincided with enhanced glacial meltwater discharge (Keigwin et al. 1991). Although meltwater discharge cannot be considered as a steady-state process, the results of Fairbanks (1989) suggest that at the end of the last ice-age the rate of melt-water discharge exceeded $0.1 \mathrm{~Sv}$ for a period of about 6000 years (roughly between 13 en 7 kyr B.P.), i.e., a time scale comparable to the adjustment time of the global thermohaline circulation. Peaking at discharge rates of 0.30 and $0.44 \mathrm{~Sv}$, the average discharge in this period must have been close to 0.16 Sv. Being discharged primarily into the North Atlantic, this input of fresh water is comparable to a Bering Strait salt export of no less than $\sigma_{b s}^{*}=-5.7 \mathrm{~Sv}$ psu, with peaks of -10 and $-15 \mathrm{~Sv}$ psu. In view of Fig. 12, this would mean a threat to the stability of the NPP circulation in the Atlantic, in favor of the modified solution of Fig. 13 (middle panel) or the SPP (Fig. 13, middle panel).

The result that the Southern Ocean buoyancy exchange stabilizes the overturning circulation indicates that the present-day Atlantic overturning may be more stable than suggested by the 3-box model of Shaffer and Bendtsen (1994), and the low resolution GCM of Weaver and Hughes (1994). In both models, present-day (and Eemian) forcing could sustain more than one circulation, among which the northern and southern sinking solutions. In the model of Shaffer and Bendtsen (1994) the northern sinking solution could be destabilized in favor of a southern sinking circulation by an increase of Bering Strait inflow to 1.1 Sv. In the model of Hughes and Weaver (1994), transitions between northern and southern sinking states could be induced by increasing the stochastic component of the surface freshwater flux. In both papers it is suggested that a warmer climate (like the Eemian, or that implied by global warming scenarios) would enhance the hydrological cycle, and thereby increase the threat of dramatic climate change. However, if the Southern Ocean interocean fluxes, and Agulhas Leakage in particular, indeed stabilize the present-day circulation to such an extent that other circulations cannot exist under present-day (or future) forcing, then our climate may be more stable than thought. 


\section{Acknowledgments}

Beverly de Cuevas and Andrew Coward (Southampton Oceanographic Centre, Southampton, U.K.) kindly provided the output of the OCCAM model. Peter-Jan van Leeuwen (IMAU) and two reviewers are thanked for useful discussions and comments. WW and WR were supported by the Dutch National Research Program on Global Change, NRP II grant 013001237.10. The contribution of HD was sponsored by NWO PIONIER Grant 030-76-187. All computations were performed on the CRAY Y-MP C98 at the Academic Computer Centre (SARA) Amsterdam, the Netherlands, within the project SC-480. Use of these computing facilities was sponsored by the Stichting Nationale Computerfaciliteiten (National Computing Facilities Foundation, NCF), with financial support from the Nederlandse Organisatie voor Wetenschappelijk Onderzoek (Netherlands Organization for Scientific Research, NWO). 


\section{Appendix A}

\section{Atlantic interocean exchange in OCCAM}

The spatial distribution and amplitudes of the heat and salt sources, that are used in our model to parameterize the heat and salt exchange, are (partly) based on the interocean exchange in the high-resolution General Circulation model OCCAM. The Ocean Circulation and Climate Advanced Modelling (OCCAM) project is a high-resolution modeling effort at the Southampton Oceanographic Centre, aimed at the development of global ocean models suitable for climate studies. The OCCAM model is a modified version of the Bryan-Cox-Semtner code (Webb et al. 1998), and has a resolution of $0.25^{\circ}$ in both longitude and latitude, and 36 levels in the vertical. Details of the model are described in Webb et al. (1998), and more information about the model and products can be found at www.soc.soton.ac.uk/JRD/OCCAM.

In the first main run, OCCAM has been integrated for 14 years. During the first 4 years, the model was in a robust diagnostic mode, and the fields of temperature and salinity were restored to the climatologies of Levitus (1982), Levitus and Boyer (1994) and Levitus et al. (1994). The model was run in prognostic mode for ten more years. The last 6 years have been released for analysis, and a 6-year average of the dynamical fields serves as a climatology of the model. Obviously, the dynamical fields cannot have reached an equilibrium in 14 years of integration. Saunders et al. (1999) analyzed the model drift in OCCAM, and reported a rise in global temperature of $0.02^{\circ} \mathrm{C}$ per year. The short integration period prevents the thermohaline fields from drifting away too far from the observation-based climatologies. Analysis of the meridional transports in the Pacific (Saunders et al. 1999) has shown that there is considerable storage of heat in this basin, consistent with the general temperature rise. The storage of freshwater in the Pacific turned out to be small, but the meridional salt transport in the Pacific showed variations in the order of $2 \mathrm{~Sv}$ psu, about $10 \%$ of the $21.5 \mathrm{~Sv}$ psu net salt transport through the Bering Strait. Our analysis of the thermohaline structures and the major current systems on the $20^{\circ} \mathrm{E}$ and $70^{\circ} \mathrm{W}$ sections indicates that they agree reasonably well with observations (Weijer 2000). We therefore believe that a (cautious) use of the fluxes in OCCAM as basis for the source distributions in this study is justified.

[Table A1 about here.]

To study the exchange between the Atlantic and the rest of the World Ocean, we analyzed the transports across the $20^{\circ} \mathrm{E}$ and $70^{\circ} \mathrm{W}$ sections, bounding the Atlantic sector of the Southern Ocean. Temperature $(T)$, salinity $(S)$ and zonal velocity $(u)$ on these sections have kindly been made available by the OCCAM group. Table A1 shows the volume, heat and salt fluxes through the main (sub)sections in OCCAM. The $20^{\circ} \mathrm{E}$ section is divided into an Agulhas part (AGU), and a part comprising the ACC and the Weddell Gyre (ACC). The bounding latitude $\theta_{0}$ between these subsections is based on the first zero-crossing of the cumulative volume transport relative to the 
African continent (Thompson et al. 1997). Due to rounding $\theta_{0}$ to the nearest grid point, the volume flux through the AGU section is not completely zero. The heat and salt fluxes are calculated with respect to the Atlantic mean temperature $\left(T^{\prime}=T-T_{m}\right)$ and salinity $\left(S^{\prime}=S-S_{m}\right)$. This guarantees that the basin-averaged temperature and salinity (and potential energy) are not affected by exchanging water with these basinaveraged properties (Weijer et al. 1999). We calculated $T_{m}=3.86^{\circ} \mathrm{C}$ and $S_{m}=34.94$ psu from the Levitus (1982) climatology.

\section{Appendix B}

\section{The source amplitudes}

In our model, we solve for circulation in a meridional plane. In fact, the 2D Boussinesq equations are equivalent to the 3D equations per zonal meter when zonal boundaries, rotation and zonal gradients are absent. So in order to make OCCAM heat and salt input compatible with this meridional-slice approach, we have to think of these sources as being distributed over the width of the Atlantic. The approach used to convert the flux divergences of Table A1 into the dimensionless source amplitudes and distributions is as follows: first, we introduce the dimensional sources, $\widetilde{Q}_{q}^{r}(\theta, \tilde{z}), r \in\{T, S\} ; q \in$ $\{a g u, a c c\}\left(\right.$ in $\left.\mathrm{Wm}^{-3}, \mathrm{gm}^{-3} \mathrm{~s}^{-1}\right)$. These sources are written as:

$$
\begin{aligned}
& \widetilde{Q}_{q}^{T}(\theta, \tilde{z})=\widetilde{\tau}_{q} Q_{q}^{T}(y, z) \\
& \widetilde{Q}_{q}^{S}(\theta, \tilde{z})=\widetilde{\sigma}_{q} Q_{q}^{S}(y, z) .
\end{aligned}
$$

The (dimensionless) distribution functions $Q_{q}^{r}$ are constructed so that their integral over the meridional/depth plane is 1 . The parameters $\widetilde{\tau}$ and $\widetilde{\sigma}$ thus control the net input of heat or salt. They are related to the integrated fluxes of Table A1 via:

$$
\begin{aligned}
\widetilde{\tau}_{a g u} & =-{\overline{u T^{\prime}}}^{20 E, A G U} / H L W_{a g u} \\
\widetilde{\sigma}_{a g u} & =-{\overline{u S^{\prime}}}^{20 E, A G U} / H L W_{a g u} \\
\widetilde{\tau}_{a c c} & =-\left({\overline{u T^{\prime}}}^{20 E, A C C}-{\overline{u T^{\prime}}}^{70 W}\right) / H L W_{a c c} \\
\widetilde{\sigma}_{a c c} & =-\left({\overline{u S^{\prime}}}^{20 E, A C C}-{\overline{u S^{\prime}}}^{70 W}\right) / H L W_{a c c} .
\end{aligned}
$$

Here, $W_{a g u}$ and $W_{a c c}$ denote the approximate widths of the Atlantic at the latitudes where the exchange takes place. The Agulhas exchange takes place at about $40^{\circ} \mathrm{S}$, where the Atlantic is approximately $80^{\circ}$ wide $\left(W_{a g u}=6.85 \cdot 10^{6} \mathrm{~m}\right)$, whereas the ACC exchange takes place at, say, $50^{\circ} \mathrm{S}$, where the width of the Atlantic is close to $90^{\circ}$ $\left(W_{a c c}=6.46 \cdot 10^{6} \mathrm{~m}\right)$.

Finally, the dimensional amplitudes are scaled according to:

$$
\tau_{q}=\frac{H^{2}}{\kappa_{v} \rho_{0} c_{p} \Delta T} \tilde{\tau}_{q} \quad ; \quad \sigma_{q}=\frac{\lambda H^{2}}{\kappa_{v} \rho_{0} \Delta S} \tilde{\sigma}_{q} .
$$


Combining the flux amplitudes in Table A1 with characteristic values of Table 1, this leads to $\tau_{a g u}=6.27, \tau_{a c c}=-2.14, \sigma_{a g u}=0.95$ and $\sigma_{a c c}=-0.64$.

A 0.5 Sv net surface freshwater loss from the Atlantic (Baumgartner and Reichel 1975) may be converted into a virtual net input of salt in the dimensionless units of our model as well. The average width $B$ of a basin of $60^{\circ}$ degrees wide (ranging from $60^{\circ} \mathrm{S}$ to $60^{\circ} \mathrm{N}$ ) is $5.54 \cdot 10^{6} \mathrm{~m}$, so that the net evaporation per square meter amounts to $\tilde{I}^{S}=6.74 \cdot 10^{-9} \mathrm{~m} \mathrm{~s}^{-1}$. This amount is equivalent to a dimensionless net surface salt flux $I^{S}$ of -1.94 , when the following scaling is applied (Weijer et al. 1999, their Eq. $(10))$ :

$$
I^{S}=-\frac{\lambda H S_{s}}{\kappa_{v} \Delta S} \tilde{I}^{S}
$$

Bering Strait salt export equals $V_{b s}\left(S_{m}-S_{b s}\right)$, and amounts to $2.05 \mathrm{~Sv}$ psu in OCCAM $\left(V_{b s}=0.675 \mathrm{~Sv}\right.$ and $S_{b s}=31.9 \mathrm{psu}$, Saunders et al. (1999)), and to 1.95 Sv psu in the real ocean $\left(V_{b s}=0.8 \mathrm{~Sv}\right.$ and $S_{b s}=32.5 \mathrm{psu}$, Coachman and Aagaard (1988)). Supposing the Atlantic to be $60^{\circ}$ wide, we have a salt sink at $60^{\circ} \mathrm{N}$ of $\tilde{\sigma}_{b s}=-0.12 \mathrm{~g}$ $\mathrm{m}^{-2} \mathrm{~s}^{-1}$. This is equivalent to a dimensionless net flux of $\sigma_{b s}=-0.36$, when (Weijer et al. 1999, their Eq. (13)):

$$
\sigma_{b s}=\frac{\lambda H^{2}}{\kappa_{v} L \Delta S \rho_{0}} \tilde{\sigma}_{b s}
$$

\section{Appendix C}

\section{The source distributions}

The spatial distributions of the Agulhas and ACC sources are based on the interocean fluxes in OCCAM as well. Of course, the detailed distribution of the heat and salt fluxes is too complicated to be of direct use for our simple model. Instead we try to capture the main characteristics of the sources in a simple analytical function. First we separate the distributions in a $y$-dependent part and a $z$-dependent part:

$$
Q_{q}^{r}(y, z)=g_{q}(y) f_{q}^{r}(z) \quad r \in\{T, S\} ; q \in\{a g u, a c c\}
$$

The meridional distributions $g_{a g u}(y)$ and $g_{a c c}(y)$ of the Agulhas and ACC sources are modeled by:

$$
g_{q}(\theta(y))=\frac{1}{I_{q}} \exp \left[-\left(\frac{\theta-\theta_{q}}{\sigma_{q}}\right)^{2}\right] \quad q \in\{a g u, a c c\}
$$

where $\theta_{q}$ and $\sigma_{q}$ denote the center and the meridional width of the sources. These are taken to be $-40^{\circ}$ and $5^{\circ}$ for the Agulhas sources $(q=a g u)$ and $-50^{\circ}$ and $10^{\circ}$ for the ACC sources $(q=a c c)$. The coefficient $I_{q}$ is the integral of the exponential:

$$
I_{q}=\frac{1}{2} \sqrt{\pi} \sigma_{q}\left[\operatorname{erf}\left(\frac{60-\theta_{q}}{\sigma_{q}}\right)+\operatorname{erf}\left(\frac{60+\theta_{q}}{\sigma_{q}}\right)\right] \quad q \in\{a g u, a c c\}
$$

so that the integral of $g_{q}(y)$ equals 1 . 
[Figure C1 about here.]

[Figure C2 about here.]

The vertical profiles of the source distributions are based on the zonal heat and salt transports across the different (sub)sections in OCCAM. For the Agulhas sources, the meridionally integrated transports across the $20^{\circ} \mathrm{E}$ AGU subsection are used. For the ACC sources, the difference is taken between the meridionally integrated transports across the $20^{\circ} \mathrm{E}$ ACC subsection and the $70^{\circ} \mathrm{W}$ section. The latter thus give the flux divergences within the ACC. These meridionally integrated transports are shown in Figs. C1 and C2 (solid lines). The Agulhas heat source profile (Fig. C1, upper panel) shows strong heat input in the upper $1000 \mathrm{~m}$. The ACC heat sink profile (Fig. C1, lower panel) is characterized by heat export from the upper layer, and heat input in the intermediate layer. The heat exchange on deeper levels is very small. The Agulhas salt flux profile (Fig. C2, upper panel) shows strong salt input at thermocline levels. Also visible is a minimum in the eastward salt transport at the depths of the AAIW, and a constant eastward salt transport at deep and bottom water levels. The ACC salt flux divergence curve (Fig. C2, lower panel) shows a similar structure, but of opposite sign. Here we have a shallow export, an input of salt at intermediate depths, and an export at the deeper levels.

Using a least-squares method, we fitted a simple analytical function $\tilde{f}_{q}^{r}(\tilde{z})$ to the profiles of the general form:

$$
\begin{aligned}
\tilde{f}_{q}^{r}(\tilde{z}) & =\tilde{a}_{1} \cos \left(\tilde{a}_{2} \tilde{z}\right) e^{\tilde{a}_{3} \tilde{z}}+\tilde{a}_{4} \\
& =\tilde{a}_{1}\left[\cos \left(a_{2}(z-1)\right) e^{a_{3}(z-1)}+a_{4}\right] \\
& \equiv \tilde{a}_{1} I_{f} f_{q}^{r}(z) \quad r \in\{T, S\} ; q \in\{a g u, a c c\}
\end{aligned}
$$

[Table C1 about here.]

The term $I_{f}=a_{3} /\left(a_{2}^{2}+a_{3}^{2}\right)+a_{4}$ is the integral of the expression between the brackets, making the integral of $f_{q}^{r}(z)$ equal to 1 . The values that yield the best fit of Eq. (C4) to the heat and salt flux profiles are tabulated in Table C1.

Figures $\mathrm{C} 1$ and $\mathrm{C} 2$ show that the best-fit approximations reproduce the characteristic features of the fluxes in OCCAM very well.

\section{Appendix D}

\section{The energy balance}

The response of the overturning circulation to the Agulhas heat and salt sources can be explained by looking at their contribution to the potential energy balance. The internal 
buoyancy sources add an extra term to the potential energy balance, Eq. (14) of Weijer et al. (1999):

$$
\frac{d U}{d t}=<B_{z}>-<w B>+I^{B}-<z Q^{B}>.
$$

With buoyancy $B$ defined as $T-S$, and $<$. $>$ denoting volume integration, this equation states that the basin-integrated potential energy $U$ of the system can change due to vertical diffusion of buoyancy, vertical advection of buoyancy, buoyancy fluxes through the surface $\left(I^{B}=I^{T}-I^{S}\right.$, at $\left.z=1\right)$, and internal sources of buoyancy $\left(Q^{B}=\right.$ $\left.Q^{T}-Q^{S}\right)$. In steady state, $d U / d t=0$ and $I^{T}=<Q^{T}>=\tau_{a g u}+\tau_{a c c} ; I^{S}=<Q^{S}>=$ $\sigma_{a g u}+\sigma_{a c c}\left(+\sigma_{b s}\right)$. The buoyancy production term $\langle w B>$ converts potential to kinetic energy, and is roughly proportional to $\left(\psi_{\max }^{*}\right)^{2}$ (Dijkstra and Molemaker 1997). Since the model is in the advective regime, changes in the external forcing (here $I^{B}$ and $<z Q^{B}>$ ) are balanced by $\left\langle w B>\right.$, rather than by $\left\langle B_{z}>\right.$ (Weijer et al. 1999). The overturning strength therefore responds directly to changes in these external forcing terms, and thus to changes in the amplitudes (and vertical distributions) of the applied buoyancy sources.

The Agulhas heat source (with amplitude $\tau_{\text {agu }}$ ) generates net surface cooling at a rate $I^{T}=\tau_{a g u}$. Since $z \leq 1$ and thus $\left(I^{T}-<z Q^{T}>\right)=\tau_{a g u}\left(1-<z Q_{a g u}^{T}\right)>0$, the subsurface heat source and the surface cooling constitute a net source of potential energy, proportional to $\tau_{a g u}$. This energy is converted into kinetic energy of the flow when the heat is advected from the (subsurface) source to the surface, enhancing $<$ $w B>$.

When the Agulhas salt flux is changed, $I^{S}$ is kept constant, and only $\left\langle z Q^{S}\right\rangle$ is changed. In the cold, hybrid and warm water scenarios, changes in the Agulhas salt input are balanced by an extra source in the ACC region, say $Q_{a c c}^{\prime S}(y, z)$ with amplitude $\sigma_{a c c}^{\prime}=1-\sigma_{a g u}$. We can write:

$$
\begin{aligned}
<z Q^{S}> & =\sigma_{a g u}<z Q_{a g u}^{S}>+\sigma_{a c c}^{\prime}<z Q_{a c c}^{\prime S}> \\
& =\sigma_{a g u}\left[<z Q_{a g u}^{S}>-<z Q_{a c c}^{\prime S}>\right]+<z Q_{a c c}^{\prime S}>, \quad z \in[0,1]
\end{aligned}
$$

If the shallow salt source is balanced by a deep salt sink (i.e. the warm water scenario), than the term between brackets is positive, and potential energy is supplied to the system, proportional to $\sigma_{\text {agu }}$ (note that $<z Q^{B}>\propto-<z Q^{S}>$ ). Due to the advective (downward) salt transport from the subsurface source to the deep sink, potential energy is released and converted into kinetic energy of the flow. If, on the other hand, the salt is removed at a shallow level (i.e. the cold water scenario), there is hardly any effect on the energy balance since the term between brackets is almost zero. This explains why the warm water scenario generates strong sensitivity of the overturning circulation, and why the cold water scenario generates hardly any response at all (Fig. 6). 


\section{References}

Baumgartner, A., and E. Reichel, 1975: The world water balance, Elsevier, 179 pp.

Berger, W. H. and G. Wefer, 1996: Expeditions into the past: Paleoceanographic studies in the South Atlantic. The South Atlantic: present and past circulation, G. Wefer et al., Eds., Springer, 363-410.

Boebel, O., C. Schmid, G. Podestá, and W. Zenk, 1999: Intermediate water in the Brazil-Malvinas Confluence Zone: A Lagrangian view. J. Geophys. Res., 104, 21062-21082.

Broecker, W. S., D. M. Peteet and D. Rind, 1985: Does the ocean-atmosphere system have more than one stable mode of operation? Nature, 315, 21-26.

Broecker, W. S., 1991: The great ocean conveyor. Oceanogr., 4, 79-89.

Bryan, F., 1986: High-latitude salinity effects and interhemispheric thermohaline circulations. Nature, 323, 301-304.

Coachman, L. K., and K. Aagaard, 1988: Transports through Bering Strait: annual and interannual variability. J. Geophys. Res., 93, 15535-15539.

Dansgaard, W., S. J Johnsen, H. B. Clausen, D. Dahl-Jensen, N. S. Gundestrup, C. U. Hammer, C. S. Hvidberg, J. P. Steffensen, A. E. Sveinbjörnsdottir, J. Jouzel and G. Bond, 1993: Evidence for general instability of past climate from 250-kyr ice-core record. Nature, 364, 218-220.

De Ruijter, W. P. M., 1982: Asymptotic analysis of the Agulhas and Brazil Current systems. J. Phys. Oceanogr., 12, 361-373.

De Ruijter, W. P. M., A. Biastoch, S. S. Drijfhout, J. R. E. Lutjeharms, R. P. Matano, T. Pichevin, P. J. van Leeuwen and W. Weijer, 1999: Indian-Atlantic inter-ocean exchange: Dynamics, estimation and impact. J. Geophys. Res., 104, 2088520910.

Dijkstra, H. A., and M. J. Molemaker, 1997: Symmetry breaking and overturning oscillations in thermohaline driven flows. J. Fluid Mech., 331, 169-198.

Dijkstra, H. A., and J. D. Neelin, 2000: Imperfections of the thermohaline circulation: latitudinal asymmetry and preferred northern sinking. J. Climate, 13, 366-382.

Fairbanks, R. G., 1989: A 17,000-year glacio-eustatic sea level record: influence of glacial melting rates on the Younger Dryas event and deep-ocean circulation. Nature, 342, 637-642. 
Flores, J.-A., R. Gersonde and F. J. Sierro, 1999: Pleistocene fluctuations in the Agulhas Current Retroflection based on the calcareous plankton record. Marine Micropaleontology, 37, 1-22.

Gordon, A. L., 1985: Indian-Atlantic transfer of thermocline water at the Agulhas Retroflection. Science, 227, 1030-1033.

Gordon, A. L., 1986: Interocean exchange of thermocline water. J. Geophys. Res., 91, 5037-5046.

Gordon, A. L., R. F. Weiss, W. M. Smethie Jr. and M. J. Warner, 1992: Thermocline and intermediate water communication between the South Atlantic and Indian Oceans. J. Geophys. Res., 97, 7223-7240.

Griffies, S. M., and E. Tziperman, 1995: A linear thermohaline oscillator driven by stochastic atmospheric forcing. J. Climate, 8, 2440-2453.

Howard, W. R., and W. L. Prell, 1992: Late quaternary surface circulation of the southern Indian Ocean and its relationship to orbital variations. Paleoceanogr., 7, 79-117.

Hughes, T. M. C., and A. J. Weaver, 1994: Multiple equilibria of an asymmetric two-basin ocean model. J. Phys. Oceanogr., 24, 619-637.

Keigwin, L. D., G. A. Jones and S. J. Lehman, 1991: Deglacial meltwater discharge, North Atlantic deep circulation, and abrupt climate change. J. Geophys. Res., 96, 16811-16826.

Levitus, S., 1982: Climatological Atlas of the World Ocean. NOAA Prof. Paper No. 13, U.S. Govt. Printing Office, 173 pp.

Levitus, S., and T. P. Boyer, 1994: World Ocean Atlas 1994, Volume 4, Temperature. NOAA Atlas NESDIS 4, 117 pp.

Levitus, S., R. Burgett and T. P. Boyer, 1994: World Ocean Atlas 1994, Volume 3, Salinity. NOAA Atlas NESDIS 3, 99 pp.

Manabe, S., and R. J. Stouffer, 1988: Two stable equilibria of a coupled oceanatmosphere model. J. Climate, 1, 841-866.

Marotzke, J., and J. Willebrand, 1991: Multiple equilibria of the global thermohaline circulation. J. Phys. Oceanogr., 21, 1372-1385.

McWilliams, J. C., 1996: Modeling the oceanic general circulation. Ann. Rev. Fl. Mech., 28, 215-248. 
Park, Y.-H., and L. Gamberoni, 1997: Cross-frontal exchange of Antarctic Intermediate Water and Antarctic Bottom Water in the Crozet Basin. Deep-Sea Res. II, 44, 963-986.

Rahmstorf, S., 1994: Rapid climate transitions in a coupled ocean-atmosphere model. Nature, 372, 82-85.

Rahmstorf, S., 1996: On the freshwater forcing and transport of the Atlantic thermohaline circulation. Climate Dyn., 12, 799-811.

Rahmstorf, S., J. Marotzke and J. Willebrand, 1996: Stability of the thermohaline circulation. The warm water sphere of the North Atlantic, W. Krauss, Ed., Bornträger, 129-158.

Rintoul, S. R., 1991: South Atlantic interbasin exchange. J. Geophys. Res., 96, 26752692.

Sarntheim, M., K. Winn, S. J. A. Jung, J.-C. Duplessy, L. Labeyrie, H. Erlenkeuser and G. Ganssen, 1994: Changes in east Atlantic deepwater circulation over the last 30,000 years: Eight time slice reconstructions. Paleoceanogr., 9, 209-267.

Saunders, P. M., A. C. Coward and B. A. de Cuevas, 1999. Circulation of the Pacific Ocean seen in a global ocean model (OCCAM). J. Geophys. Res., 104, 1828118299.

Schmitz Jr., W. J., 1995: On the interbasin-scale thermohaline circulation. Rev. Geophys., 33, 151-173.

Shaffer, G., and J. Bendtsen, 1994: Role of the Bering Strait in controlling North Atlantic ocean circulation and climate. Nature, 367, 354-357.

Stocker, T. F., and D. G. Wright, 1991a: Rapid transitions of the ocean's deep circulation and climate change. Nature, 351, 729-732.

Stocker, T. F., and D. G. Wright, 1991b: A zonally averaged ocean model for the thermohaline circulation. Part II: Interocean circulation in the Pacific-Atlantic basin system. J. Phys. Oceanogr., 21, 1725-1739.

Stocker, T. F., D. G. Wright and L. A. Mysak, 1992: A zonally averaged, coupled ocean-atmosphere model for paleoclimate studies. J. Clim., 5, 773-797.

Stommel, H., 1961: Thermohaline convection with two stable regimes of flow. Tellus, 13, 224-230.

Thompson, S. R., D. P. Stevens and K. Döös, 1997: The importance of interocean exchange south of Africa in a numerical model. J. Geophys. Res., 102, 33033315. 
Thual, O., and J. C. McWilliams, 1992: The catastrophe structure of thermohaline convection in a two-dimensional fluid model and a comparison with low-order box models. Geophys. Astrophys. Fluid Dyn., 64, 67-95.

Tziperman, E., 1997: Inherently unstable climate behaviour due to weak thermohaline ocean circulation. Nature, 386, 592-595.

Weaver, A. J., J. Marotzke, P. F. Cummins and E. S. Sarachik, 1993: Stability and variability of the thermohaline circulation. J. Phys. Oceanogr., 23, 39-60.

Weaver, A. J., and T. M. C. Hughes, 1994: Rapid interglacial climate fluctuations driven by North Atlantic ocean circulation. Nature, 367, 447-450.

Webb, D. J., B. A. de Cuevas and A. C. Coward, 1998: The first main run of the OC$C A M$ global ocean model. Internal report of James Renell Division, Southampton Oceanographic Centre, Southampton, 50 pp.

Weijer, W., W. P. M. de Ruijter, H. A. Dijkstra and P. J. van Leeuwen, 1999: Impact of interbasin exchange on the Atlantic overturning circulation. J. Phys. Oceanogr., 29, 2266-2284.

Weijer, W., 2000: Impact of interocean exchange on the Atlantic overturning circulation. PhD Dissertation, Utrecht University.

Weijer, W., W. P. M. de Ruijter, A. Sterl, and S. S. Drijfhout, 2000: Response of the Atlantic overturning circulation to South Atlantic sources of buoyancy. Global and Planetary Change, submitted.

Winton, M., and E. S. Sarachik, 1993: Thermohaline oscillations induced by strong steady salinity forcing of ocean general circulation models. J. Phys. Oceanogr., 23, 1389-1410.

Zaucker, F., T. F. Stocker, and W. S. Broecker, 1994: Atmospheric freshwater fluxes and their effect on the global thermohaline circulation. J. Geophys. Res., 99, $12443-12457$. 


\section{List of Figures}

1 Profiles of prescribed atmospheric temperature $T^{*}$ and surface salt flux $F^{S}$ as a function of latitude. . . . . . . . . . . . . . . . 32

2 Wire plot representations of the source/sink distributions. a) Heat source $Q^{T}$ according to Eq. (7a), with $\tau_{a g u}=-\tau_{a c c}=1$. b) Salt source $Q^{S}$ according to Eq. (7b), with $\sigma_{a g u}=-\sigma_{a c c}=1$. Note that the individual distributions $Q_{a g u, a c c}^{T, S}$ are normalized so that their integrals over the $(y, z)$-domain equal $1 . \ldots \ldots \ldots \ldots \ldots$

3 Streamfunction (upper panel), temperature (middle panel) and salinity (lower panel) fields for the standard solution. Contouring increments are $2 \mathrm{~Sv}$ for streamfunction (solid lines denote clockwise circulation), 2.5 $\mathrm{K}$ for temperature (dashed line denotes $15^{\circ} \mathrm{C}$ isotherm) and $0.5 \mathrm{psu}$ for salinity (dashed line denotes $35 \mathrm{psu}$ isohaline). Note the pool of cold and fresh water in the ACC area. . . . . . . . . . . . . . . . . 34

4 Observed zonally averaged Atlantic sea-surface salinity (Levitus 1982), compared with the surface salinity of the solution with standard source configuration ('no Bering Strait'), and a solution where a realistic $\left(\sigma_{b s}^{*}=\right.$ -2.0 Sv psu) Bering Strait salt export is included ('Bering Strait'). . . . 35

5 Schematic illustration of the fate of Agulhas Leakage water for the cold and warm water scenarios. In the cold water scenario, Agulhas Leakage water recirculates in the South Atlantic Subtropical Gyre, and leaves the Atlantic at the same level. In the warm water scenario, it takes part in the overturning circulation and leaves the Atlantic as NADW. . . . . . 36

6 The overturning strength as a function of the Agulhas salt source strength for the three scenarios mentioned in the text. Note that $\sigma_{a g u}^{*}$ decreases to the right. . . . . . . . . . . . . . . . . 37

$7 \quad$ Bifurcation diagram of the symmetric model without internal sources and zero net surface salt flux $\left(I^{S}=0\right)$. Control parameter is the surface salt flux amplitude $\sigma_{s}$, and the solutions are monitored with the streamfunction value $\left(\psi_{r h s}^{*}\right)$ in the (arbitrarily chosen) point $(\theta, \tilde{z})=\left(42^{\circ},-450 \mathrm{~m}\right)$ on the northern hemisphere. Negative values denote clockwise circulation. Stable branches are solid, unstable branches are dashed. Indicated are the thermally driven branch (TH), the salinity driven branch (SA), and the northern sinking and southern sinking pole-to-pole circulations (NPP and SPP). The squares denote the pitchfork bifurcations $P_{1}$ and $P_{2}$, whereas the limit points $L_{S}$ and $L_{N}$ are indicated by dots. The open circles indicate the position of the solutions shown in Fig. 8, whereas the crosses at $\sigma_{s}=10$ correspond to those on the 'no sources' curve of Fig. 12. Note that $\sigma_{s}=10$ is a characteristic value for present-day $E-P$ in the Atlantic. . . . . . . . . . . . . . . . . . . . . 38 
8 Three solutions of the symmetrical model, corresponding to the open circles in the bifurcation diagram of Fig. 7. Shown are a thermally driven circulation ( $\mathrm{TH}, \sigma_{s}=0$, upper panel), a pole-to-pole circulation (NPP, $\sigma_{s}=10$, middle panel), and a salinity driven solution (SA, $\sigma_{s}=20$, lower panel). Streamfunctions are normalized with respect to their maxima, contour interval is 0.1 , solid (dashed) contours denote (anti-) clockwise

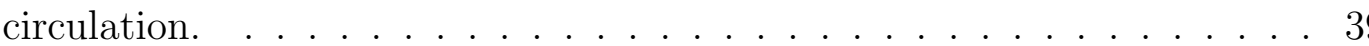

$9 \quad$ Bifurcation diagrams of the model with a positive $\left(\tau_{a g u}^{*}=0.02 \mathrm{PW}\right.$, upper panel) and a negative $\left(\tau_{\text {agu }}^{*}=-0.02 \mathrm{PW}\right.$, lower panel) heat source in the Agulhas region. Due to the loss of the equatorial symmetry, the pitchfork bifurcations $P_{1}$ and $P_{2}$ are broken up into limit points $L_{1}$ and $L_{2}$. A positive heat source in the Agulhas region (upper panel) stabilizes the northern sinking solution (NPP) and connects this branch continuously to the salinity driven solution (SA), and via limit points $L_{1}$ and $L_{N}$ to the branch of thermally driven solutions (TH). A negative heat source hinders the NPP circulation and isolates its branch in parameter space. . 40

10 The position of the limit points $L_{S}, L_{N}$ and $L_{2}$ in $\sigma_{s}-\tau_{a q u}^{*}$-space (upper panel) and in $\sigma_{s}-\sigma_{a g u}^{*}$-space (lower panel). The heat and salt source distributions are identical and decay exponentially with depth. A net salt source is compensated by an offset in the surface salt flux. For negative $\tau_{a g u}^{*}$ or positive $\sigma_{a g u}^{*}$ the NPP solution only exists in the window bounded by $L_{N}$ and $L_{2}$, and is completely absent for values smaller than $\tau_{a g u}^{*}=-0.04 \mathrm{PW}$ or larger than $\sigma_{a g u}^{*}=0.7 \mathrm{~Sv}$ psu. For positive $\tau_{a g u}^{*}$ or negative $\sigma_{a g u}^{*}$ the NPP solution cannot be clearly distinguished from the SA and TH branches, since NPP transforms continuously into the SA branch, and the limit points $L_{1}$ and $L_{N}$ disappear for increasing source amplitudes. . . . . . . . . . . . . . . . . . . . . 41

11 Regime diagram showing the areas in $\sigma_{a g u}^{*}-\tau_{a g u}^{*}$-space where NPP and SPP solutions exist. Heat input and salt export in the Agulhas region $\left(\tau_{a g u}^{*}>0\right.$ and $\left.\sigma_{a g u}^{*}<0\right)$ favor the existence of the NPP solutions, whereas heat export and salt input $\left(\tau_{a g u}^{*}<0\right.$ and $\left.\sigma_{a g u}^{*}>0\right)$ hinder their existence. The arrows point approximately in the direction (-21.2 Sv psu, 0.74 PW) of the standard source configuration (upper arrow) and the configuration (-32.6 Sv psu, -0.34 PW) without Agulhas Leakage (lower arrow). Both configurations are situated in the 'unique NPP' regime. . . . . . . . . . . 42 
12 Value of $\psi_{r h s}^{*}$ as a function of the amplitude of the Bering Strait salt export, $-\sigma_{b s}^{*}$. The curve denoted 'ACC+Agulhas' is constructed with all Southern Ocean sources present, whereas the 'ACC only'-curve is constructed with the ACC distributions only. Increased Bering Strait salt export is compensated by decreased ACC salt export. In the 'no sources' case, no Southern Ocean sources are present, and increased Bering Strait salt export is compensated by decreased surface salt input to retain the basic symmetry of the model. A realistic value of $-\sigma_{b s}^{*}$ is $2.0 \mathrm{~Sv}$ psu, so shutting off Agulhas Leakage would bring the model close to the regime where the NPP and SPP solutions coexist. The open circles indicate the positions of the solutions shown in Fig. 13, whereas the crosses at $\sigma_{b s}^{*}=0$

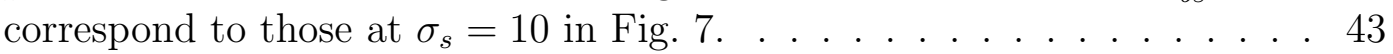

13 Streamfunctions of the solutions corresponding to the open circles on the curve 'ACC+Agulhas' of Fig. 12. Upper panel shows an NPP solution on the lower branch in Fig. $12\left(-\sigma_{b s}^{*}=6.7 \mathrm{~Sv}\right.$ psu $)$, middle panel shows a solution with the downwelling shifted to the Subtropical latitudes $\left(-\sigma_{b s}^{*}=9.2 \mathrm{~Sv}\right.$ psu $)$, and the lower panel is an SPP solution $\left(-\sigma_{b s}^{*}=6.7 \mathrm{~Sv} \mathrm{psu}\right)$. Streamfunctions are normalized with respect to their maxima, contour interval is 0.1 , and solid (dashed) contours denote (anti-)clockwise circulation. . . . . . . . . . . . . . . 44

C1 Vertical profiles of the Agulhas (upper panel) and the ACC (lower panel) heat fluxes, according to OCCAM (solid lines), and the best-fit approximations $\tilde{f}_{a g u}^{T}$ and $\tilde{f}_{a c c}^{T}$ (Eq. (C4); dashed lines). . . . . . . . . 45

C2 Vertical profiles of the Agulhas (upper panel) and the ACC (lower panel) salt fluxes, according to OCCAM (solid lines), and the best-fit approximations $\tilde{f}_{a g u}^{S}$ and $\widetilde{f}_{a c c}^{S}$ (Eq. (C4); dashed lines). . . . . . . . . 46 


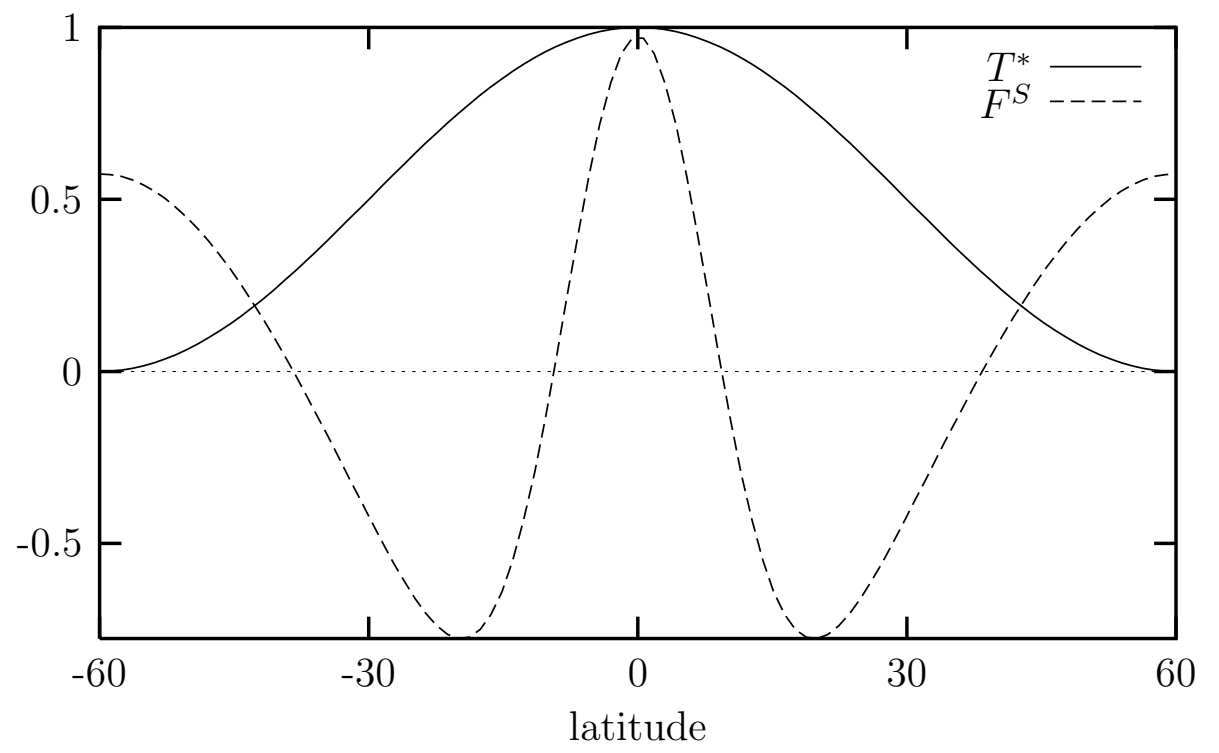

Figure 1 
a)

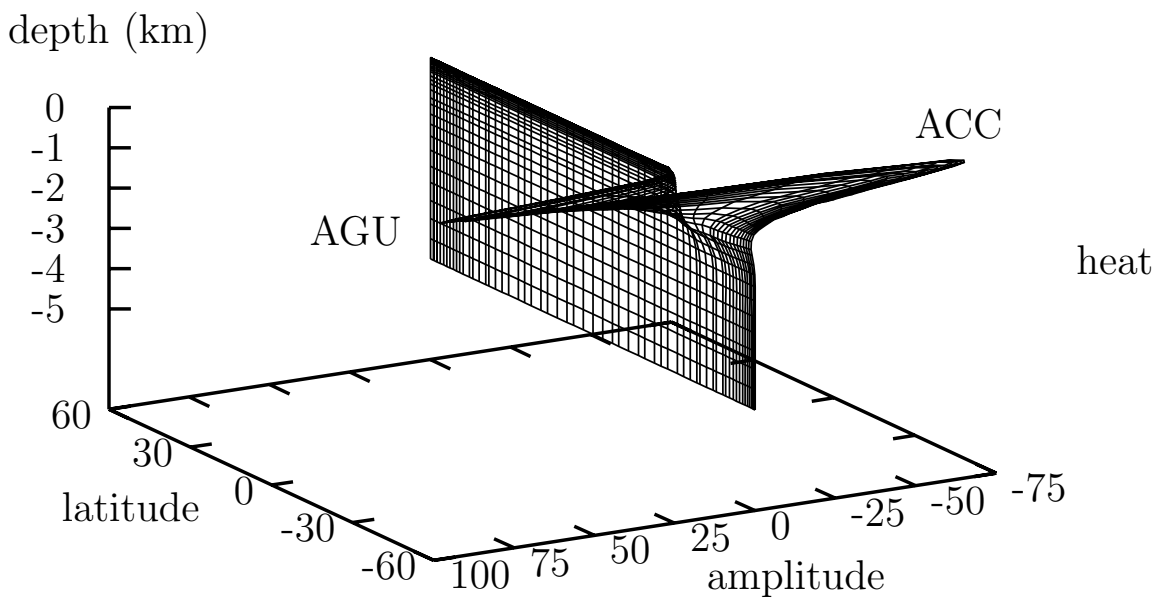

b)

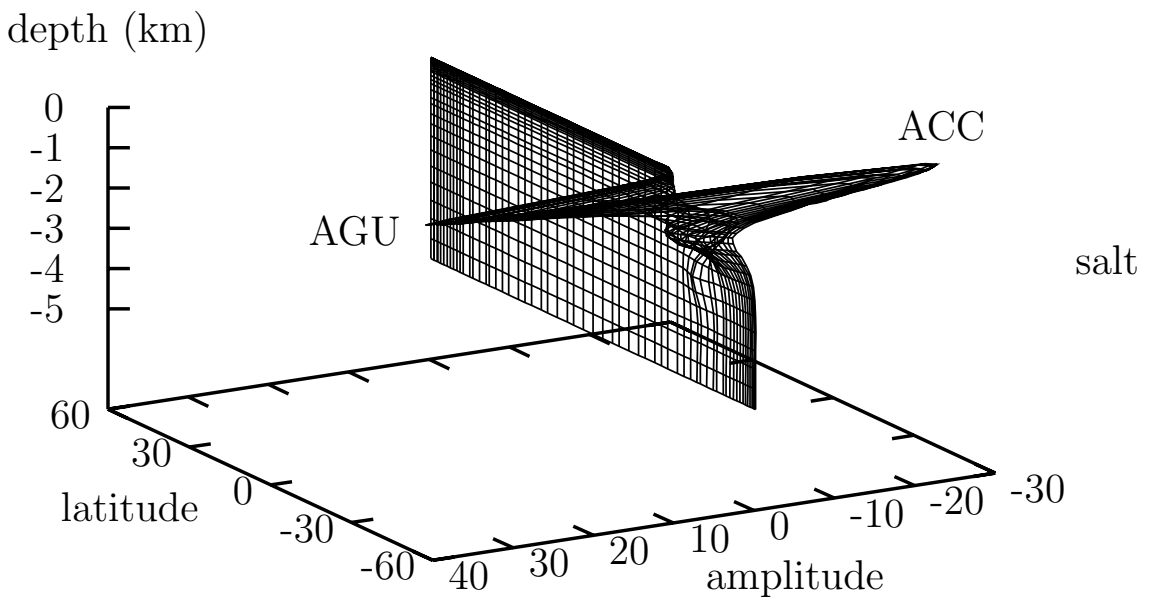

Figure 2 

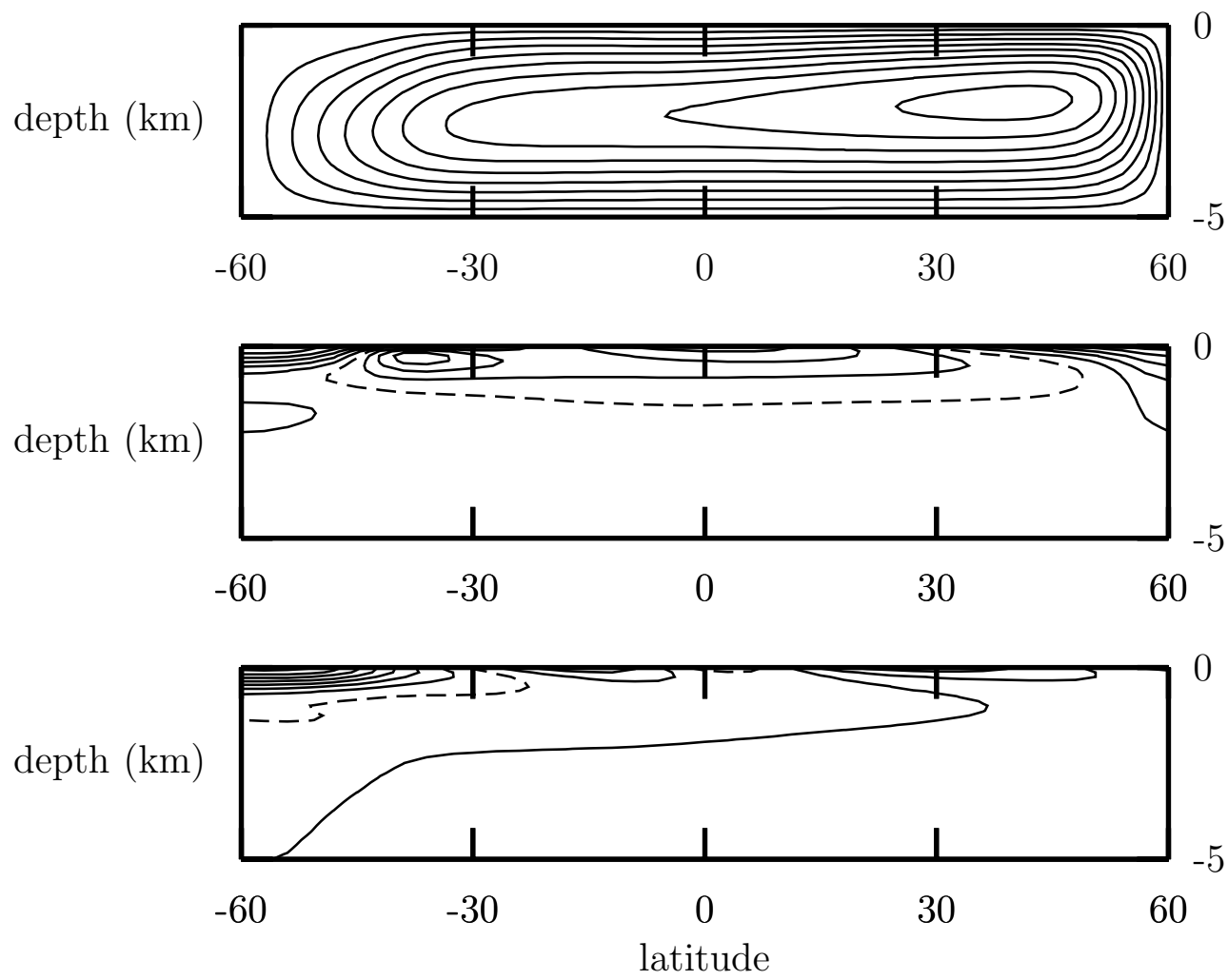

Figure 3 


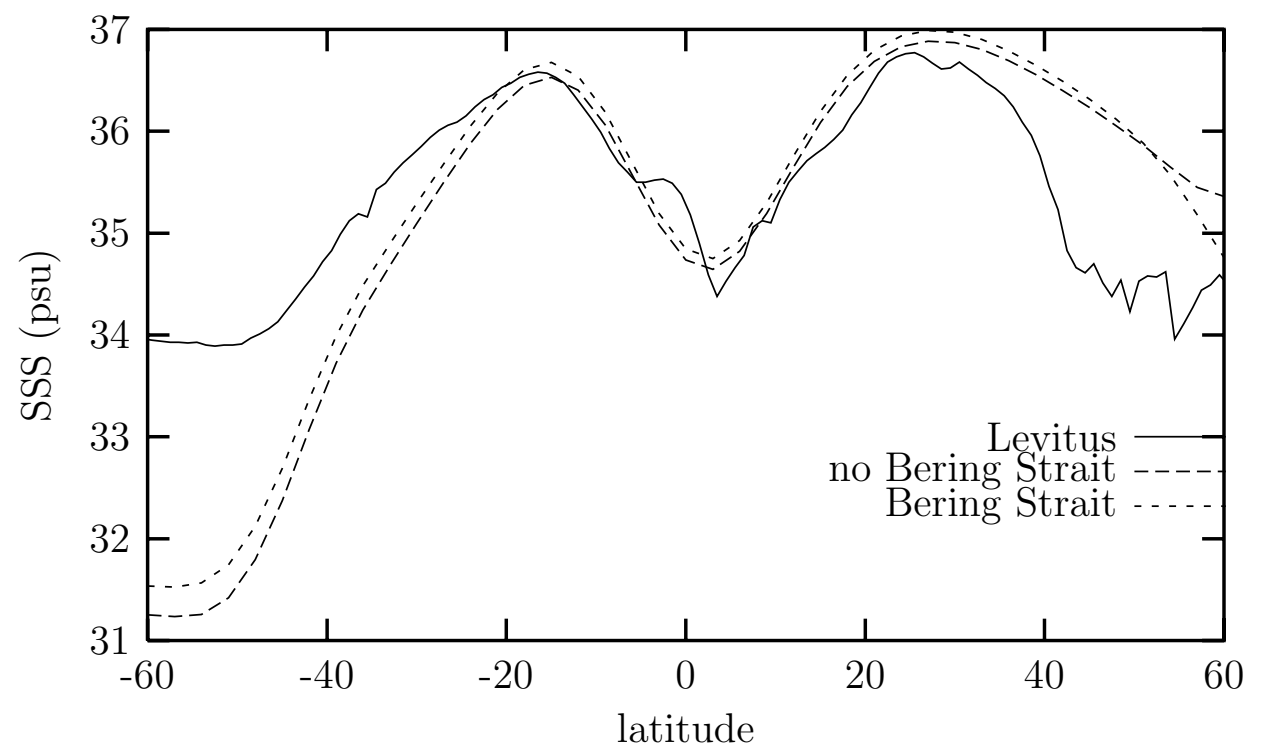

Figure 4 


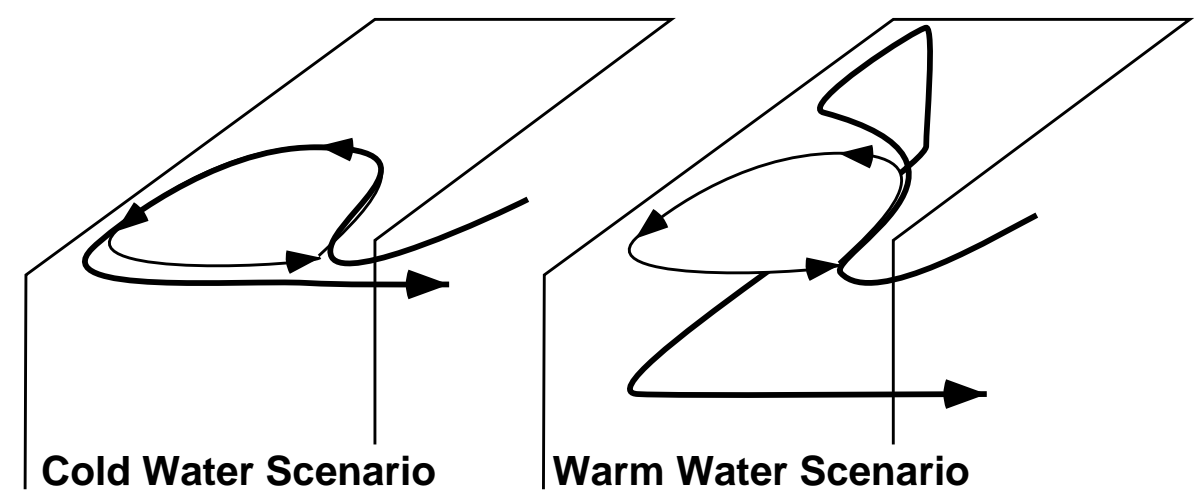

Figure 5 


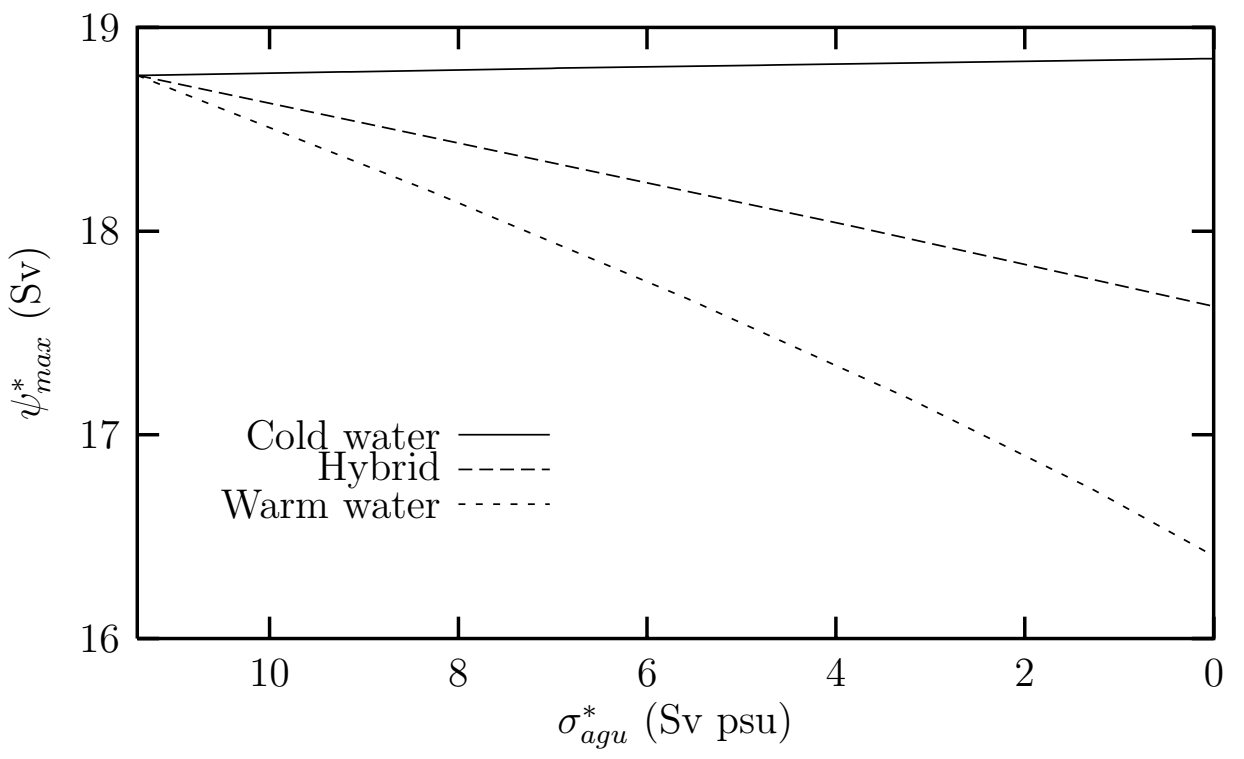

Figure 6 


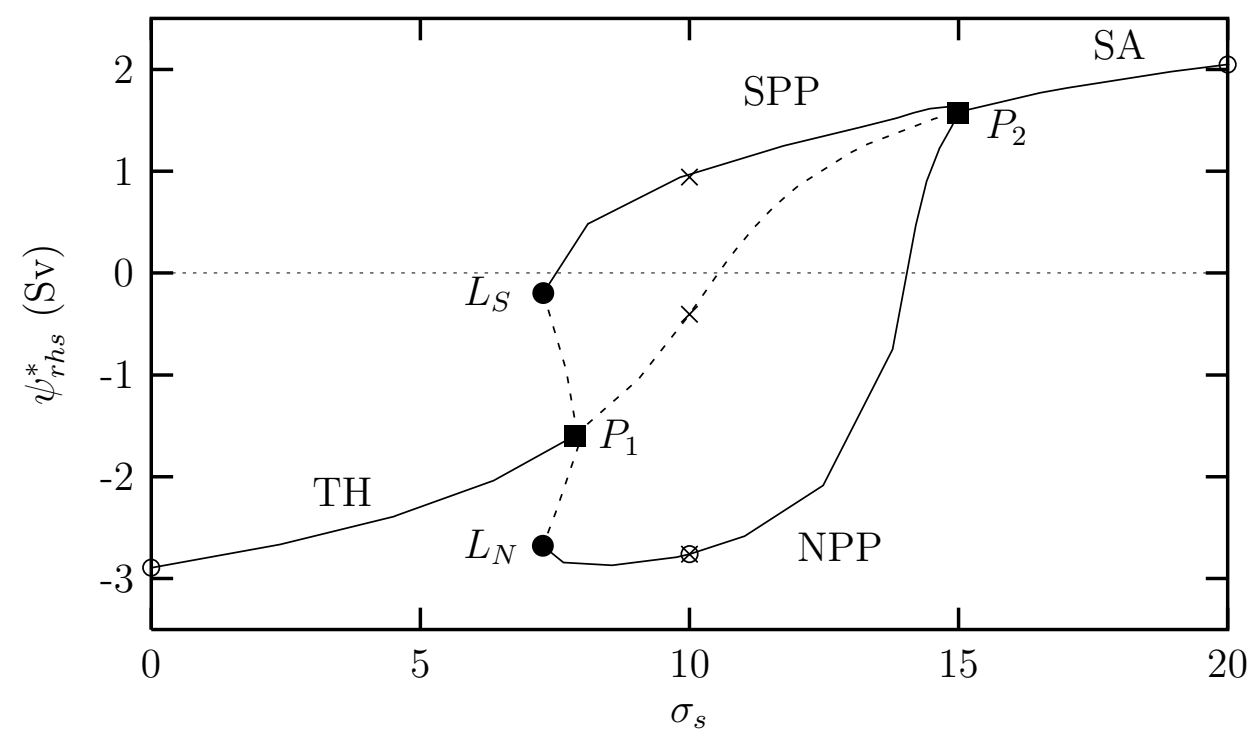

Figure 7 

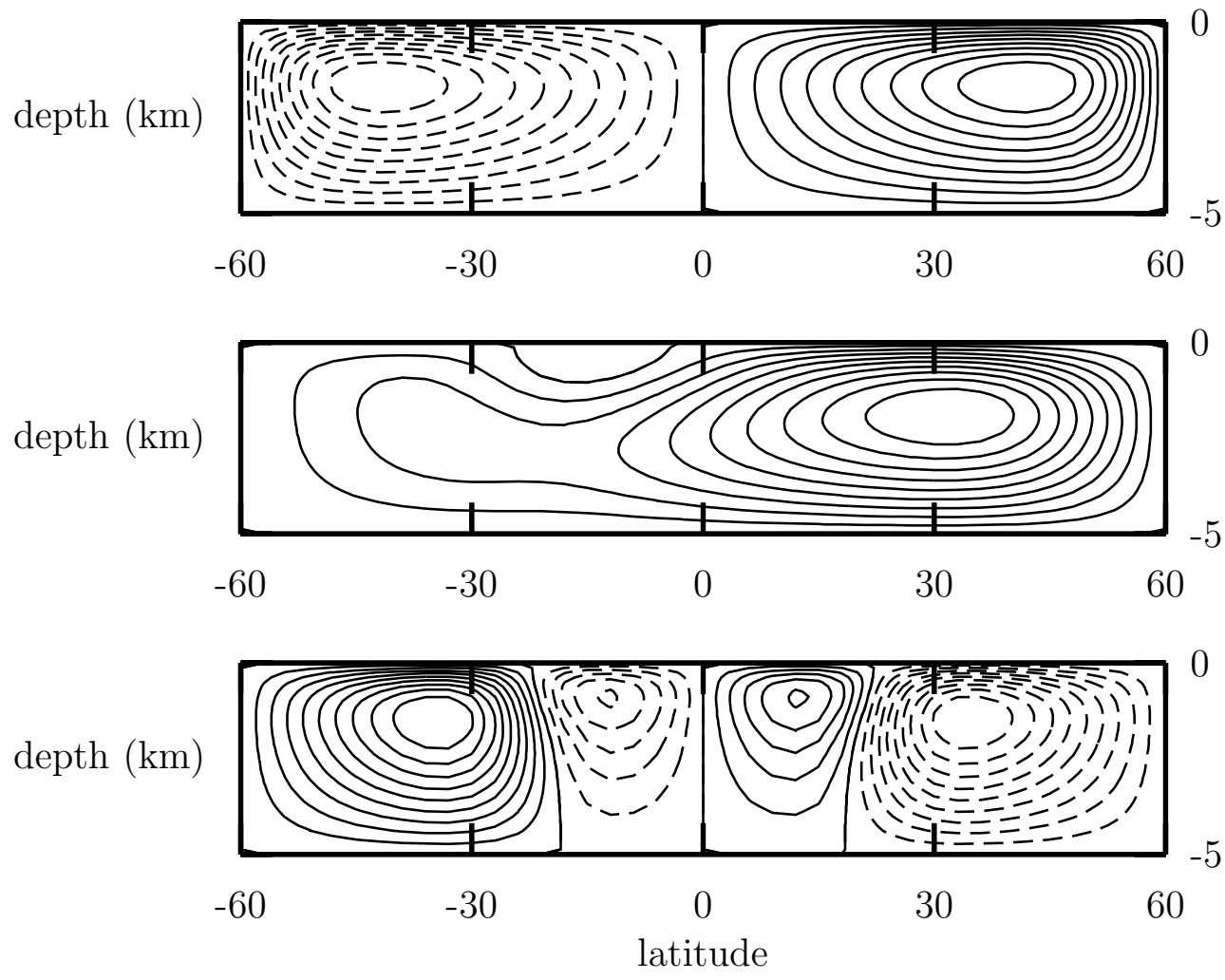

Figure 8 

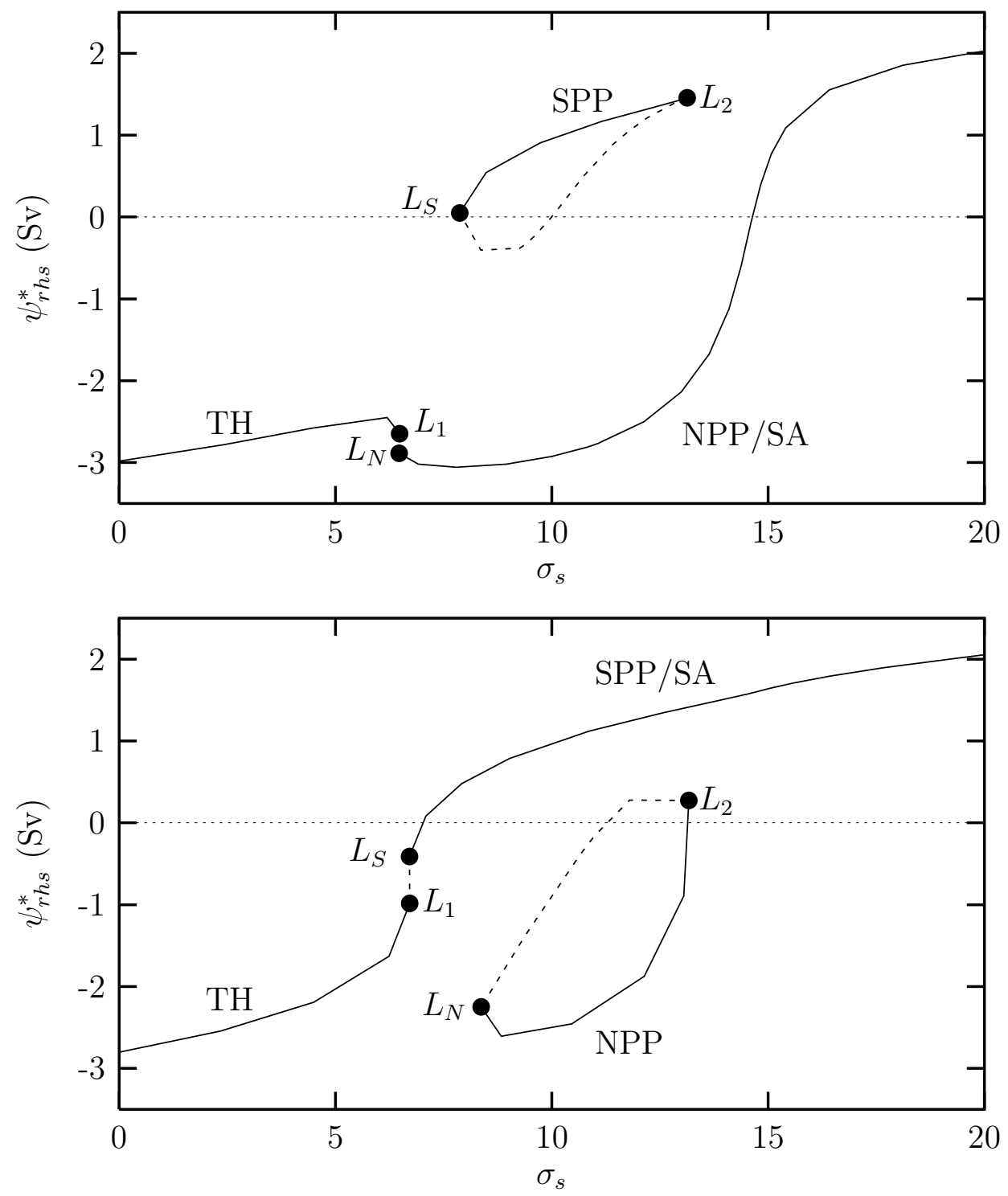

Figure 9 

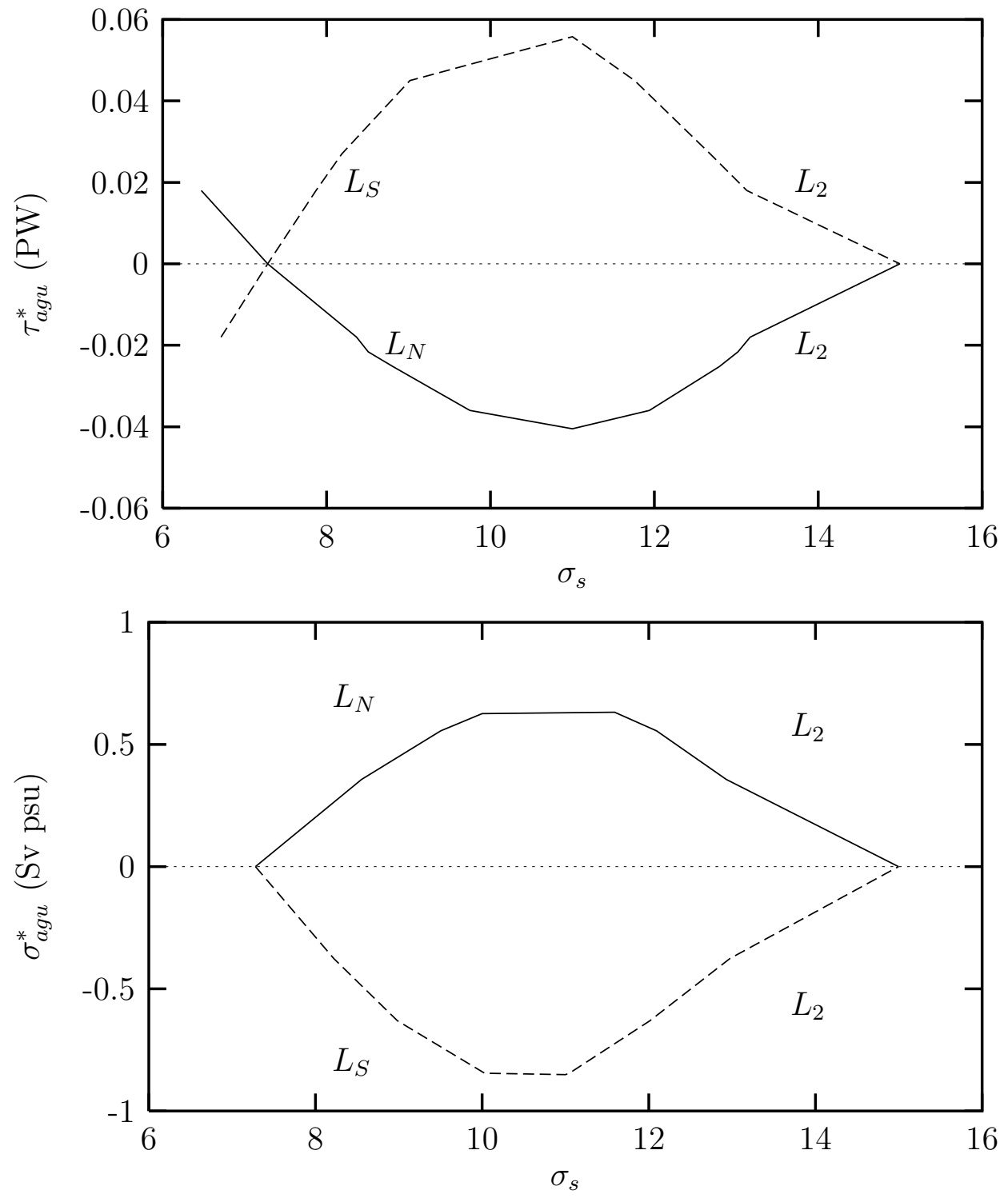

Figure 10 


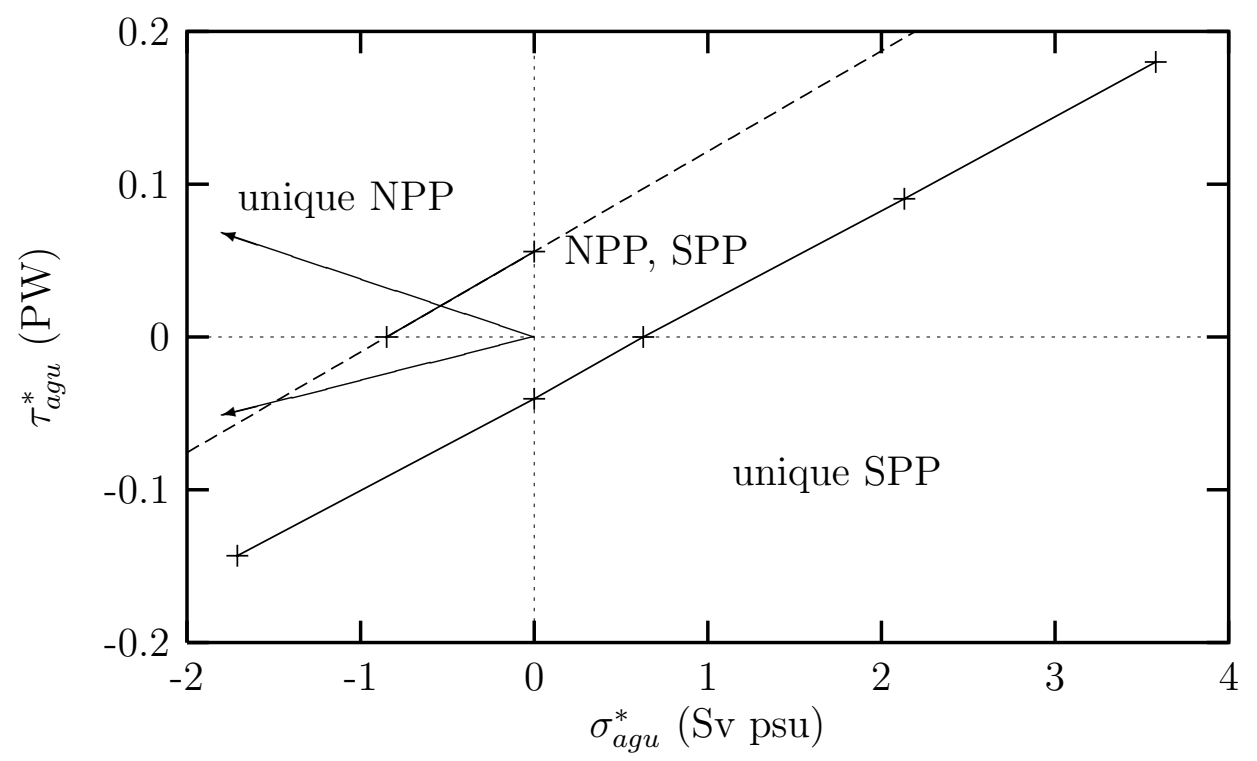

Figure 11 


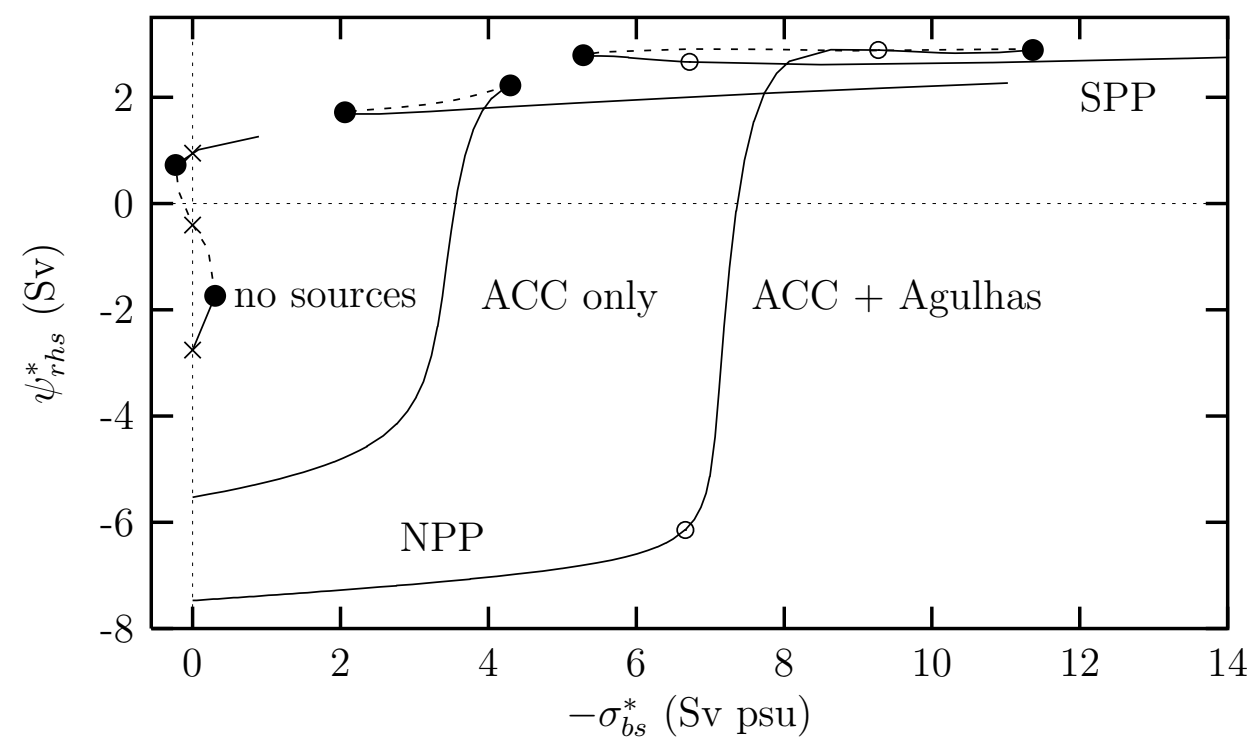

Figure 12 

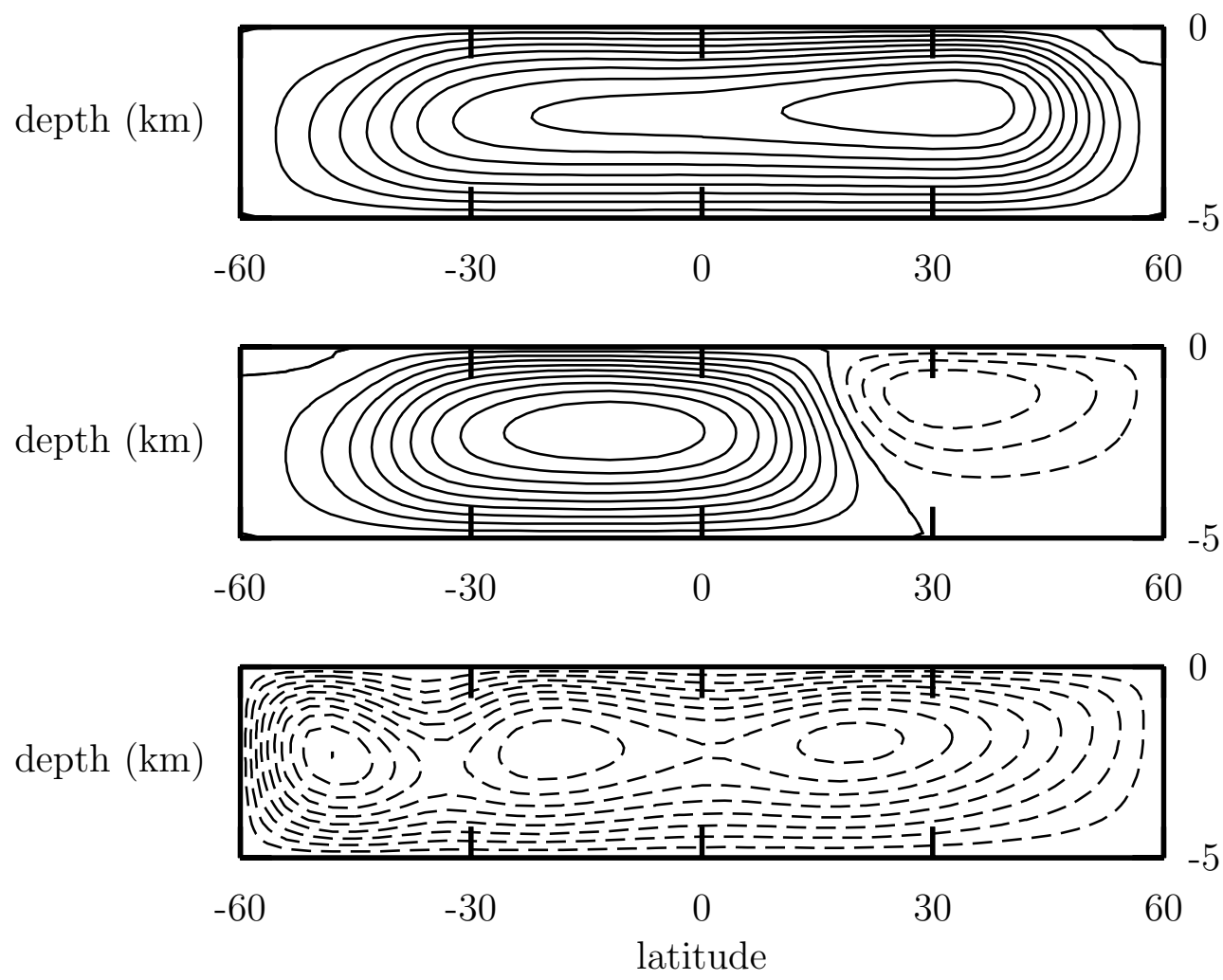

Figure 13 

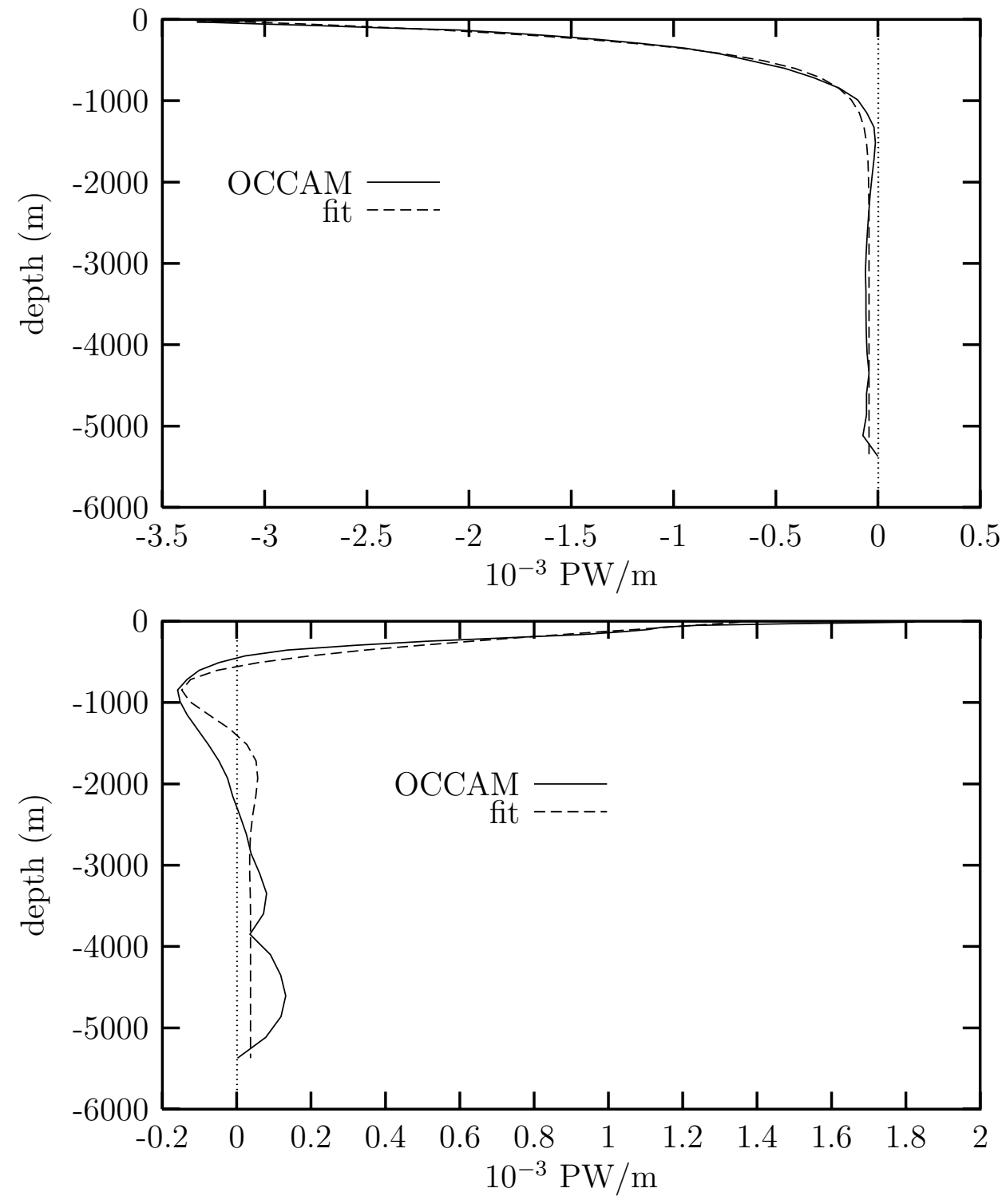

Figure C1 

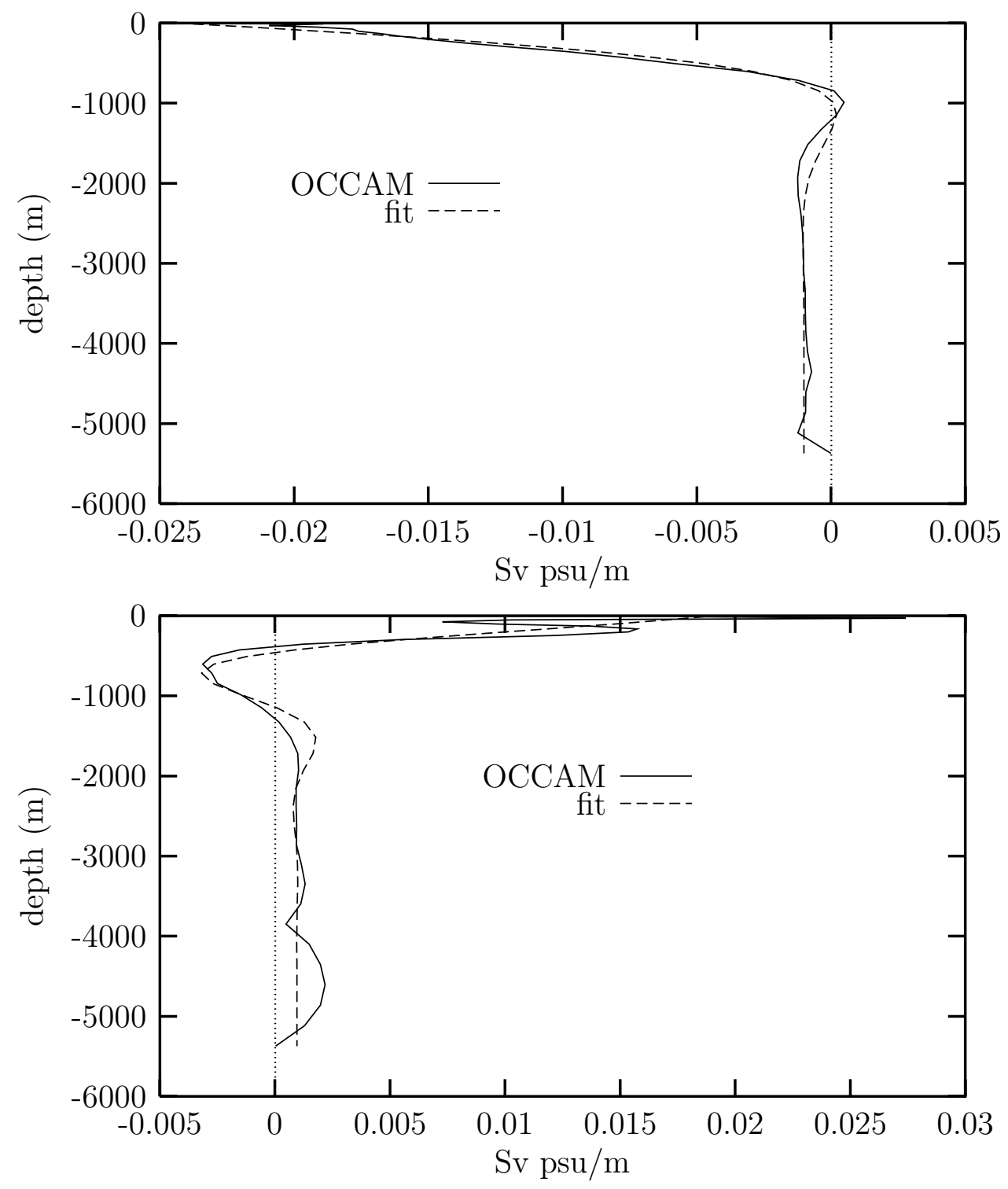

Figure C2 


\section{List of Tables}

1 Symbols and characteristic values of dimensional and non-dimensional parameters used in this model. . . . . . . . . . . . . . . . . . . . . . 48

2 The amplitudes of the Agulhas $\left(\tau_{a g u}\right)$ and ACC $\left(\tau_{a c c}\right)$ heat sources used in this study. Dimensional values are calculated from the OCCAM climatology (see Appendix A). Dimensionless values are the equivalent heat source amplitudes, as determined in Appendix B. The conversion factors can be used to relate the dimensionless source amplitudes $\tau$ to their dimensional equivalents $\tau^{*}$ (in PW). The lower row gives the values applied in the standard source configuration. . . . . . . . . . . . . . 49

3 The amplitudes of the Agulhas $\left(\sigma_{a g u}\right)$ and ACC $\left(\sigma_{a c c}\right)$ salt sources, as well as of the Bering Strait $\left(\sigma_{b s}\right)$ and surface $\left(I^{S}\right)$ salt fluxes used in this study. Dimensional values for the Agulhas and ACC salt sources are calculated from the OCCAM climatology (see Appendix A). The net surface salt flux $I^{S}$ is consistent with a $0.5 \mathrm{~Sv}$ net surface freshwater export (Baumgartner and Reichel 1975). The Bering Strait salt flux amplitude is consistent with the Coachman and Aagaard (1988) estimate. Dimensionless values are the equivalent salt source and flux amplitudes as determined in Appendix B. The conversion factors can be used to relate the dimensionless source amplitudes $\sigma$ to their dimensional equivalents $\sigma^{*}$ (in $\mathrm{Sv} \mathrm{psu}$ ). The lower row gives the values applied in the standard source configuration. Note that the value of $\sigma_{a c c}$ is increased in the standard configuration to close the salt balance. . . . . . . . . . . . . 50

A1 Transports of volume, heat and salt across the $70^{\circ} \mathrm{W}$ and $20^{\circ} \mathrm{E}$ OCCAM sections in the Southern Ocean. Heat and salt fluxes are calculated with respect to the Atlantic mean temperature $\left(T_{m}\right)$ and salinity $\left(S_{m}\right)$, calculated from Levitus (1982). . . . . . . . . . . . . . . . . . . . 51

C1 Best-fit parameter values for the heat and salt flux profiles. . . . . . . . . 52 


\begin{tabular}{lcll}
\hline \hline Parameter & Symbol & Value & Unit \\
\hline Characteristic length scale & $L$ & $1.34 \cdot 10^{7}$ & $\mathrm{~m}$ \\
Characteristic depth scale & $H$ & $5 \cdot 10^{3}$ & $\mathrm{~m}$ \\
Characteristic temperature range & $\Delta T$ & 25 & ${ }^{\circ} \mathrm{C}$ \\
Atlantic mean temperature & $T_{m}$ & 3.86 & ${ }^{\circ} \mathrm{C}$ \\
Characteristic salinity range & $\Delta S$ & 2 & $\mathrm{psu}$ \\
Atlantic mean salinity & $S_{m}$ & 34.94 & $\mathrm{psu}$ \\
Characteristic surface salinity & $S_{s}$ & 36 & $\mathrm{psu}$ \\
Reference density & $\rho_{0}$ & $1 \cdot 10^{3}$ & $\mathrm{~kg} \mathrm{~m}^{-3}$ \\
Heat capacity & $c_{p}$ & $4 \cdot 10^{3}$ & $\mathrm{~J} \mathrm{~kg}^{-1} \mathrm{~K}^{-1}$ \\
Vertical diffusivity & $\kappa_{v}$ & $1 \cdot 10^{-4}$ & $\mathrm{~m}^{2} \mathrm{~s}^{-1}$ \\
& & & \\
Aspect ratio & $a$ & $5 \cdot 10^{-4}$ & \\
Thermal Rayleigh number & $R a$ & $1 \cdot 10^{4}$ & \\
Prandtl number & $P r$ & 2.25 & \\
Buoyancy ratio & $\lambda$ & 0.32 & \\
Thermal relaxation constant & $b_{T}$ & 100 & \\
\hline
\end{tabular}

Table 1 


\begin{tabular}{l|cc}
\hline \hline Heat sources & $\tau_{a g u}$ & $\tau_{a c c}$ \\
\hline Dimensional (PW) & 1.15 & -0.37 \\
Dimensionless & 6.27 & -2.14 \\
Conversion factor (PW) & 0.18 & 0.17 \\
Standard source configuration & 6 & -2 \\
\hline
\end{tabular}

Table 2 


\begin{tabular}{l|cccc}
\hline \hline Salt sources & $\sigma_{a g u}$ & $\sigma_{a c c}$ & $\sigma_{b s}$ & $I_{s}^{S}$ \\
\hline Dimensional (Sv psu) & 10.85 & -6.96 & -2.0 & -18.0 \\
Dimensionless & 0.95 & -0.64 & -0.36 & -1.94 \\
Conversion factor (Sv psu) & 11.42 & 10.88 & 5.56 & 9.28 \\
Standard source configuration & 1 & -3 & 0 & -2 \\
\hline
\end{tabular}

Table 3 


\begin{tabular}{l|rrr}
\hline \hline section & Volume (Sv) & Heat (PW) & Salt (Sv psu) \\
\hline $70^{\circ} \mathrm{W}$ & 153.57 & -0.52 & -67.76 \\
$20^{\circ} \mathrm{E}$ & 154.03 & -1.31 & -71.66 \\
$\mathrm{AGU}$ & 1.66 & -1.15 & -10.85 \\
$\mathrm{ACC}$ & 152.37 & -0.15 & -60.80 \\
\hline $20^{\circ} \mathrm{E}-70^{\circ} \mathrm{W}$ & 0.46 & -0.79 & -3.90 \\
$20^{\circ} \mathrm{E}, \mathrm{ACC}-70^{\circ} \mathrm{W}$ & -1.20 & 0.37 & 6.96 \\
\hline
\end{tabular}

Table A1 


\begin{tabular}{l|rrrr}
\hline \hline & $\tilde{f}_{a g u}^{T}$ & $\tilde{f}_{a c c}^{T}$ & $\tilde{f}_{a g u}^{S}$ & $\tilde{f}_{a c c}^{S}$ \\
\hline$\tilde{a}_{1}\left(10^{-3} \mathrm{PW} \mathrm{m}^{-1} / 10^{-2} \mathrm{~Sv} \mathrm{psu} \mathrm{m}{ }^{-1}\right)$ & -3.42 & 1.35 & -2.33 & 1.81 \\
$\tilde{a}_{2}\left(10^{-3} \mathrm{~m}^{-1}\right)$ & 0.00 & 3.00 & 2.05 & 3.72 \\
$\tilde{a}_{3}\left(10^{-3} \mathrm{~m}^{-1}\right)$ & 3.72 & 2.11 & 2.28 & 1.89 \\
$\tilde{a}_{4}\left(10^{-5} \mathrm{PW} \mathrm{m} \mathrm{m}^{-1} / 10^{-3} \mathrm{~Sv} \mathrm{psu} \mathrm{m}{ }^{-1}\right)$ & -4.34 & 3.70 & -1.01 & 0.96 \\
\hline$a_{2}=H \tilde{a}_{2}$ & 0.0 & 15.0 & 10.3 & 18.6 \\
$a_{3}=H \tilde{a}_{3}$ & 18.6 & 10.6 & 11.4 & 9.5 \\
$a_{4}=\tilde{a}_{4} / \tilde{a}_{1}$ & 0.013 & 0.028 & 0.043 & 0.053 \\
\hline
\end{tabular}

Table C1 